Artigos

Volume 11 - $2021 \mid$ n. 6

\title{
Reformulações e Implementação do Fies (1999-2020):
}

\section{um preâmbulo}

\author{
Rodrigo Meleu das Neves \\ Nalú Farenzena \\ Denise Lindstrom Bandeira \\ Universidade Federal do Rio Grande do Sul (UFRGS), Porto Alegre/RS - Brasil
}

\section{Resumo}

O artigo trata de reformulações e da implementação do Fundo de Financiamento Estudantil (Fies) e dos desdobramentos de sua repaginação, especialmente no que se refere ao endividamento público federal com o Programa entre o segundo semestre de 2010 e o primeiro semestre de 2020. Foi adotado o método misto, com uso e geração de dados provindos de legislação, revisão bibliográfica, análise de business intelligence e triangulação de bancos de dados primários do Fundo Nacional de Desenvolvimento da Educação, da Caixa Econômica Federal e do Ministério da Educação. Verificamos, entre os achados, que o Fies revelou-se, especialmente no período entre 2011 e 2015, uma política que permitiu a prática de crowding-out, o enriquecimento de agentes privados, a nucleação do setor para gigantes educacionais e incertezas quanto ao adimplemento dos empréstimos concedidos.

Palavras-chave: Fies. Crowding-out. Creduc. Endividamento. Política de Financiamento da Educação Superior.

\section{Reformulations and Implementation of Fies (1999-2020): a preamble}

\section{Abstract}

This article deals with reformulations and the implementation of the Student Financing Fund (Fies) and the consequences of its repagination, especially regarding to the federal public debt with the Program between the second semester of 2010 and the first of 2020. The mixed method was adopted, with use and generation of data from legislation, bibliographic review, business intelligence analysis and triangulation of primary databases from the National Education Development Fund, Caixa Econômica Federal and the Ministry of Education. The research has found that Fies proved to be, especially in the period between 2011 and 2015, a policy that allowed the practice of crowding-out, the enrichment of private agents, concentrating the educational sector into giant conglomerates, while posing uncertainties to the payment of the loans granted.

Keywords: Fies. Crowding-out. Creduc. Indebtedness. Higher Education Financing Policy. 
Reformulações e Implementação do Fies (1999-2020)

\section{Introdução}

O Fundo de Financiamento Estudantil (Fies) é uma política federal de financiamento para subsidiar o acesso à educação superior a alunos que cumpram certos requisitos de ordem social e educacional, definidos de acordo com legislação específica. Analisaremos suas características mais abrangentes, bem como o seu funcionamento e alguns movimentos políticos de sua trajetória. O estudo do Fies como política social, contudo, requer a articulação de elementos dos contextos político, econômico e social que o cercam, o que é efetuado, embora de forma sintética, ao longo do texto. Realizamos coleta dos resultados econômicos da respectiva rubrica, por meio da triangulação de fontes, sinalizamos relações com outras políticas sociais e articulamos conteúdos de seus textos, nas perspectivas sincrônica e diacrônica.

O método de pesquisa que adotamos foi o misto, por combinar abordagens quantitativas e qualitativas, utilizando os pontos fortes que cada uma delas tem a oferecer, livros, artigos, documentos legais, relatórios de gestão e triangulação de bancos de dados para a apuração do percurso financeiro do Fies entre 1999 e 2019, e projeções até 2022.

\section{Creduc - o legado da política antecessora}

Entre 1980 e 1998 a educação superior registrou tímida, mas constante, expansão, salvo no ano de 1992, que apontou queda de 1,87\% nas matrículas. Em 1980, havia 1.377.286 alunos matriculados; destes, 885.054 em instituições privadas e 492.232 em estabelecimentos públicos. Já em 1998, 62,15\% dos 2.125 .958 estudantes estavam matriculados na educação superior privada (INEP, 2000a).

Entender o Fies de hoje requer uma visita ao passado recente, uma vez que a educação superior privada experimenta importante expansão desde a década de 1970, recebendo, para tal, apoio do setor público federal, o que é assim expresso por Lima et. al. (2019, p. 9): “[...] grupos educacionais privados, sempre receberam auxílios pecuniários da União, seja por meio de programas de acesso ao ensino superior, ou por um conjunto de políticas públicas". Criado a partir da Exposição de Motivos n 393/1975 (BRASIL, 1975), pelo então Ministério da Educação e Cultura (MEC), o Programa de Crédito Educativo (PCE ou Creduc) tinha por objetivo "conceder empréstimos a estudantes para o pagamento de mensalidades e o custeio de despesas durante o desenvolvimento do curso de graduação" (FNDE, 2018b).

Em termos sucintos, o Creduc operava assim: implantado no primeiro semestre de 1976, inicialmente nas Regiões Norte, Nordeste e Centro-Oeste, estendeu-se progressivamente às demais regiões (BRASIL, 2018c). Até 1983, era administrado pela Caixa Econômica Federal (CEF), pelo Banco do Brasil (BB) e outros bancos comerciais, quando o financiamento cobrava encargos anuais de $15 \%$, dos quais $12 \%$ remuneravam o agente financeiro e $3 \%$ destinavam-se a um fundo de risco do programa. A amortização do crédito utilizava Tabela Price. Na sequência, o Programa passou a ser mantido pelo orçamento do Ministério da Educação (MEC) e pelo Fundo de Assistência Social (FAS), gerido pelas loterias e administrado unicamente pela CEF. Após a promulgação da Constituição Federal (CF), em 1988, o MEC tornou-se o único mantenedor até 1992, quando o Programa foi reformulado, e, finalmente, consagrado na Lei $n^{\circ} 8.436 / 1992$ (BRASIL, 1992), que atribuiu ao MEC uma parte 
dos depósitos compulsórios do Banco Central ( $\mathrm{BCB}$ ) e outros recursos de prêmios de loterias para a manutenção e expansão ao financiamento.

Contudo, é possível reconhecer que nem tudo saiu como esperado. Em 2003, quatro anos após sua extinção, ainda havia 202.261 contratos ativos, com inadimplência orbitando em torno de $83 \%$, somando $\mathrm{R} \$ 2,1$ bilhões em aberto. Sob a carteira do MEC, que administrava outros 47.953 contratos, ainda restavam mais $R \$ 363,1$ milhões pendentes (BARROS, 2003, p. 4). Em 2005, o Creduc ainda possuía 145.363 contratos ativos, somando $\mathrm{R}$ \$ 2,4 bilhões em aberto, considerados os juros e a correção monetária do período. Para liquidar esse passivo, o governo optou por uma questionável decisão: aos adimplentes foi ofertado um desconto de $90 \%$; aos demais, e em prazo de carência, desconto de $80 \%$, desde que fosse firmada a renúncia de novos acordos (QUEIROZ, 2015). Em 1996, uma repaginação dos requisitos terminaria restringindo o acesso a estudantes tidos como carentes, até a sua revogação em 1999, com o advento do Fies. O Creduc subsidiou mais de 870 mil estudantes em sua vigência (FNDE, 2018a).

\section{Fies - percurso legal, político e financeiro}

Criado pela Medida Provisória (MP) no 1.827, de 27 de maio de 1999 (BRASIL, 1999a), convertida na Lei $n^{0} 10.260$, de 12 de julho de 2001 (BRASIL, 2001)1, o Fies é um fundo "[...] de natureza contábil, vinculado ao Ministério da Educação, destinado à concessão de financiamento a estudantes de cursos superiores não gratuitos e com avaliação positiva nos processos conduzidos pelo Ministério, de acordo com regulamentação própria", redação esta dada pela Lei no 13.530/2017 (BRASIL, 2017a) (art. 10²).

No intervalo entre 1999 e 2020, o Fies foi reformulado sob todos os aspectos: regramentos legais, política de abrangência e público-alvo: tanto no viés do seu financiamento, quanto dos critérios de contratação e distribuição. O Ministério da Economia $(\mathrm{ME})^{3}$ registra que o entendimento do impacto do Fies nas contas públicas requer atentar para seus fluxos orçamentários e financeiros, que envolvem "diversos atores, emissão de títulos públicos, pagamento de tributos e leilões de recompra de títulos excedentes", o que, em função da complexidade, dificultam seu monitoramento (BRASIL, 2017d, p. 7-8). Observamos esse caminho na Figura 1.

1 Antes da inscrição em lei, o Fies sofreu ajustes por meio das Portarias do MEC n 860, de 27 de maio de 1999 (BRASIL, 1999e) e 1.386, de 15 de setembro de 1999 (BRASIL, 1999f), além de Resolução do Conselho Monetário Nacional (CMN) $n^{\circ}$ 2.647, de 22 de setembro de 1999 (BRASIL, 1999d), como também por três Medidas Provisórias: $\mathrm{n}^{\circ}$ 1.865-2, de 29 de junho de 1999 (BRASIL, 1999b); $\mathrm{n}^{\circ} 1.972-8$, de 10 de dezembro de 1999 (BRASIL, 1999c); e n² 2.094-22, em 27 de dezembro de 2000 (BRASIL, 2000).

2 O FNDE descreve o Fies de forma discretamente diferente, expressando o acesso à Política apenas a cursos presenciais: "O Fies é um programa destinado a financiar a graduação de estudantes matriculados em cursos presenciais não gratuitos e com avaliação positiva nos processos de avaliação conduzidos pelo Ministério da Educação. O programa financia até $100 \%$ do valor dos encargos educacionais cobrados pelas instituições de ensino com adesão ao Fundo, dependendo da renda familiar mensal bruta e do comprometimento com os custos da mensalidade" (FNDE, 2018b).

3 Para fins de nomenclatura, o estudo trata o Ministério da Economia (ME) como Ministério da Fazenda (MF) até dezembro de 2018, quando foi rebatizado pela nova gestão. 
Figura 1 - Fluxograma do Fies (2017)

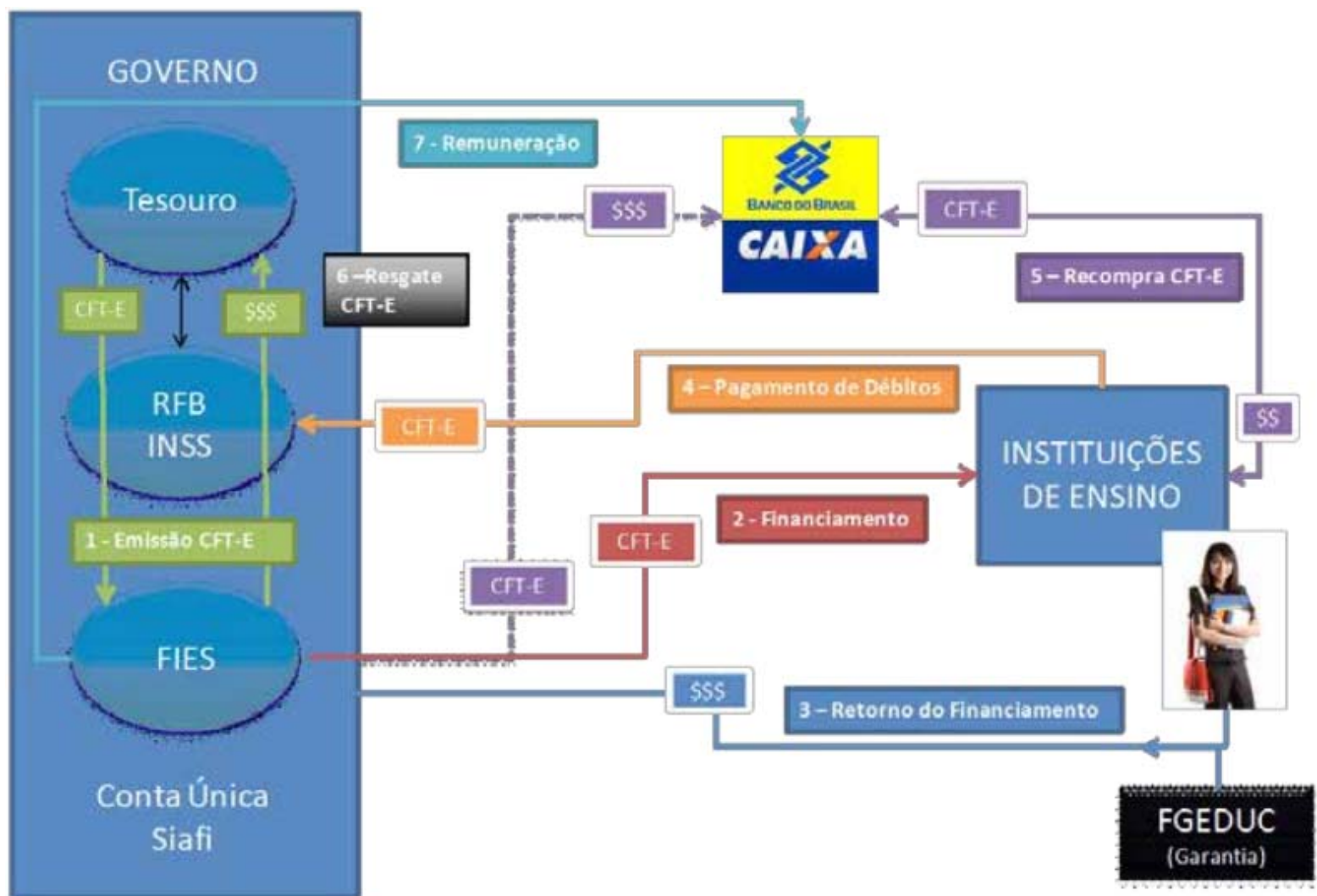

Nota: CFT-E - Certificados Financeiros do Tesouro - Série E; RFB: Receita Federal do Brasil; FGEDUC: Fundo Garantidor do Fies. Fonte: Diagnóstico Fies (BRASIL, 2017d, p. 15).

De acordo com a Figura 1, os recursos do Fies são repassados mensalmente pelo Fundo Nacional de Desenvolvimento da Educação (FNDE), em função direta aos contratos honrados pelos estudantes junto aos agentes financeiros credenciados, e o repasse é realizado junto às entidades mantenedoras das instituições de educação superior por meio de Certificados Financeiros do Tesouro - Série E (CFT-E) ${ }^{4}$. Os desembolsos ao Fies são realizados através de um sistema de aquisição de CFT junto ao Tesouro, e recompra de CFT junto às entidades mantenedoras, com observância à Lei do Fies (BRASIL, 2001).

O Fies iniciou suas atividades atribuindo à Caixa Econômica Federal (CEF) a administração e a operacionalização dos contratos ativos e passivos do Creduc, de acordo com as normas estabelecidas pelo Conselho Monetário Nacional $(\mathrm{CMN})^{5}$. No que se refere à taxa de juros cobrada no Fies, ficou em 6,5\% a.a., embora alguns cursos tenham sido

4 Certificados do Tesouro Nacional são emissões diretas de títulos, realizadas para o atendimento de finalidades específicas, definidas pelo Decreto $n^{\circ}$ 9.292, de 23 de fevereiro de 2018 (BRASIL, 2018b). Com relação ao tipo $\mathrm{E}$, especificamente aqueles títulos relacionados ao Fies, "terão como valor nominal múltiplo de $\mathrm{R} \$ 1,00$ (um real) e serão inegociáveis" (art. 15, Parágrafo Único). De acordo com o FNDE, entende-se por ordens de pagamento dessa natureza "títulos públicos emitidos pelo Tesouro Nacional, intransferíveis e que devem ser utilizados prioritariamente no pagamento de contribuições previdenciárias e demais tributos administrados pela Receita Federal" (FNDE, 2020c) (FNDE, 2019d). De acordo com Mendes (2015, p. 11-12), o CFT-E foi um mecanismo que a União encontrou para "casar a expansão do crédito educacional com um estímulo à quitação de débitos e à adimplência fiscal das escolas privadas de ensino superior".

5 Nesse período de transição entre o Creduc e o Fies, os recursos daquele seriam mantidos, vedando-se a celebração de novos contratos (BRASIL, 1999a) (arts. $2^{\circ}$ e $16^{\circ}$ ). 
Reformulações e Implementação do Fies (1999-2020)

recomendados como prioritários e passassem a ser subsidiados a juros de $3,4 \%$ a.a. (BRASIL, 2006).

O primeiro período do Fies o caracteriza como Programa pouco expressivo "tendo celebrado cerca de 530 mil contratos em seus primeiros dez anos" (ROSSETTO; GONÇALVES, 2015, p. 806), ou, assim como o Creduc, foi tido como mais uma iniciativa que seguia fora das prioridades do MEC, até 2010 (BURGARELLI, 2017, p. 43). Outra política que pode ter influenciado a baixa procura pelo Fies no período foi o Programa Universidade para Todos (Prouni).

O Prouni foi criado por meio da MP no 213/2004 (BRASIL, 2004) e institucionalizado pela redação da Lei $n^{0}$ 11.096/2005 (BRASIL, 2005). Caracteriza-se, em sua essência, como política afirmativa de acesso à educação superior de estudantes egressos do ensino médio público. Concedido semestralmente, o Prouni distribui dois terços das cotas no primeiro semestre e, o restante, no segundo, sendo destinado a estudantes de famílias de baixa renda, além de considerar critérios étnico-raciais. Identificamos que, entre 2005 e 2016, o Prouni já ofertou 2.884.503 bolsas (GILIOLI, 2017), o que nos permite afirmar com certo grau de segurança que essa política se prestou também como ação de benevolência ao setor educacional privado, possibilitando a este, inclusive, de acordo com Novaes (2017, p. 107), recuperar-se financeiramente das altas taxas de inadimplência experimentadas com o Fies em período concorrente, e, por conseguinte, obter lucros nessa transação.

De um modo geral, as matrículas na educação superior (presencial e a distância) crescem progressivamente desde 1980, com expansão de 443,54\% no período 1980-2018, o que é mais acentuado na modalidade de educação a distância (EAD), que acusa espetacular evolução desde o início dos registros, em 2000: $1.222,65 \%$ até o censo 2018 , observadas na Tabela 1. 
Tabela 1 - Evolução das matrículas Brasil (1980-2018) e dos contratos Fies (1999-2019)

\begin{tabular}{|c|c|c|c|c|c|c|c|c|c|c|c|c|c|c|}
\hline \multirow[b]{3}{*}{ Ano } & \multicolumn{6}{|c|}{$\Sigma$ MATRÍCULAS EDUCAÇÃOO SUPERIOR } & \multicolumn{8}{|c|}{$\Sigma$ FIES } \\
\hline & \multicolumn{5}{|c|}{ Presenciais e EAD } & \multirow{2}{*}{\begin{tabular}{|l|} 
Presenciais \\
Privadas (E)
\end{tabular}} & \multicolumn{4}{|c|}{ Vagas } & \multicolumn{4}{|c|}{ Contratos } \\
\hline & Públicas (A) & Privadas (B) & \begin{tabular}{|c|} 
Públicas e \\
Privadas \\
$(\mathbf{C}=\mathbf{A}+\mathbf{B})$
\end{tabular} & $\begin{array}{c}\% \text { Públicas } \\
\text { Brasil }\end{array}$ & $\begin{array}{c}\% \text { Privadas } \\
\text { Brasil }\end{array}$ & & $\begin{array}{c}\begin{array}{c}\text { Vagas } \\
\text { Oferecidas } \\
\text { (1) }\end{array} \\
\end{array}$ & $\begin{array}{c}\text { Evolução (2) / } \\
\text { ano anterior }\end{array}$ & Novas (3) & $\begin{array}{l}\text { Evolução (4) / } \\
\text { ano anterior }\end{array}$ & $\begin{array}{c}\text { Ativos } \\
\text { [RA's] (5) }\end{array}$ & \begin{tabular}{|c|}
$\%$ FIES \\
Brasil \\
Privadas \\
Presenciais
\end{tabular} & $\begin{array}{c}\text { Crescimento (6) } \\
\text { ano anterior }\end{array}$ & Microdados (7) \\
\hline 1980 & 492.232 & 885.054 & 1.377 .286 & $35,74 \%$ & $64,26 \%$ & & & & & & & & & \\
\hline 1981 & 535.810 & 850.982 & 1.386 .792 & $38,64 \%$ & $61,36 \%$ & & & & & & & & & \\
\hline 1982 & 548.388 & 859.599 & 1.407 .987 & $38,95 \%$ & $61,05 \%$ & & & & & & & & & \\
\hline 1983 & 576.689 & 862.303 & 1.438 .992 & $40,08 \%$ & $59,92 \%$ & & & & & & & & & \\
\hline 1984 & 571.879 & 827.660 & 1.399 .539 & $40,86 \%$ & $59,14 \%$ & & & & & & & & & \\
\hline 1985 & 556.680 & 810.929 & 1.367 .609 & $40,70 \%$ & $59,30 \%$ & & & & & & & & & \\
\hline 1986 & 577.632 & 840.564 & 1.418 .196 & $40,73 \%$ & $59,27 \%$ & & & & & & & & & \\
\hline 1987 & 584.965 & 885.590 & 1.470 .555 & $39,78 \%$ & $60,22 \%$ & & & & & & & & & \\
\hline 1988 & 585.351 & 918.209 & 1.503 .560 & $38,93 \%$ & $61,07 \%$ & & & & & & & & & \\
\hline 1989 & 584.414 & 934.490 & \begin{tabular}{|l|}
1.518 .904 \\
\end{tabular} & $38,48 \%$ & $61,52 \%$ & & & & & & & & & \\
\hline 1990 & 578.625 & 961.455 & 1.540 .080 & $37,57 \%$ & $62,43 \%$ & & & & & & & & & \\
\hline 1991 & 605.736 & 959.320 & \begin{tabular}{|l|}
1.565 .056 \\
\end{tabular} & $38,70 \%$ & $61,30 \%$ & & & & & & & & & \\
\hline 1992 & 629.662 & 906.126 & \begin{tabular}{|l|}
1.535 .788 \\
\end{tabular} & $41,00 \%$ & $59,00 \%$ & & & & & & & & & \\
\hline 1993 & 653.516 & 941.152 & \begin{tabular}{|l|}
1.594 .668 \\
\end{tabular} & $40,98 \%$ & $59,02 \%$ & & & & & & & & & \\
\hline 1994 & 690.450 & 970.584 & 1.661 .034 & $41,57 \%$ & $58,43 \%$ & & & & & & & & & \\
\hline 1995 & 700.540 & 1.059 .163 & \begin{tabular}{|l|}
1.759 .703 \\
\end{tabular} & $39,81 \%$ & $60,19 \%$ & & & & & & & & & \\
\hline 1996 & 735.427 & 1.133 .102 & \begin{tabular}{|l|}
1.868 .529 \\
\end{tabular} & $39,36 \%$ & $60,64 \%$ & & & & & & & & & \\
\hline 1997 & 759.182 & 1.186 .433 & \begin{tabular}{|l|}
1.945 .615 \\
\end{tabular} & $39,02 \%$ & $60,98 \%$ & & & & & & & & & \\
\hline 1998 & 804.729 & 1.321 .229 & 2.125 .958 & $37,85 \%$ & $62,15 \%$ & & & & & & & & & \\
\hline 1999 & 832.022 & 1.537 .923 & 2.369 .945 & $35,11 \%$ & $64,89 \%$ & 1.537 .923 & & & 67.202 & & 67.202 & $4,37 \%$ & & \\
\hline 2000 & 888.708 & $\begin{array}{l}1.807 .219 \\
\end{array}$ & \begin{tabular}{|l|}
2.695 .927 \\
\end{tabular} & $32,96 \%$ & $67,04 \%$ & \begin{tabular}{|l|}
1.807 .219 \\
\end{tabular} & 100.000 & & 35.299 & $-47,47 \%$ & 102.501 & $5,67 \%$ & $52,53 \%$ & \\
\hline 2001 & 944.589 & 2.091 .524 & \begin{tabular}{|l|}
3.036 .113 \\
\end{tabular} & $31,11 \%$ & $68,89 \%$ & 2.091 .524 & 60.000 & $-40,00 \%$ & 48.456 & $37,27 \%$ & 150.677 & $7,20 \%$ & $47,00 \%$ & - \\
\hline 2002 & 1.085 .977 & 2.434 .650 & 3.520 .627 & $30,85 \%$ & $69,15 \%$ & 2.428 .258 & 80.000 & $33,33 \%$ & 65.808 & $35,81 \%$ & 218.775 & $9,01 \%$ & $45,19 \%$ & \\
\hline 2003 & 1.178 .573 & 2.758 .360 & \begin{tabular}{|l|}
3.936 .933 \\
\end{tabular} & $29,94 \%$ & $70,06 \%$ & 2.750 .652 & 70.000 & $-12,50 \%$ & 49.248 & $-25,16 \%$ & 271.992 & $9,89 \%$ & $24,32 \%$ & \\
\hline 2004 & $\begin{array}{l}1.214 .317 \\
\end{array}$ & 3.009 .027 & \begin{tabular}{|l|}
4.223 .344 \\
\end{tabular} & $28,75 \%$ & $71,25 \%$ & 2.985 .405 & 50.000 & $-28,57 \%$ & 42.216 & $-14,28 \%$ & 312.027 & $10,45 \%$ & $14,72 \%$ & \\
\hline 2005 & 1.227 .788 & 3.340 .010 & \begin{tabular}{|l|}
4.567 .798 \\
\end{tabular} & $26,88 \%$ & $73,12 \%$ & 3.260 .967 & 100.000 & $100,00 \%$ & 77.202 & $82,87 \%$ & 372.038 & $11,41 \%$ & $19,23 \%$ & \\
\hline 2006 & 1.247 .733 & 3.636 .904 & 4.884 .637 & $25,55 \%$ & $74,47 \%$ & 3.467 .342 & 100.000 & $0,00 \%$ & 58.259 & $-24,54 \%$ & 377.662 & $10,89 \%$ & $1,51 \%$ & \\
\hline 2007 & 1.276 .752 & 3.973 .395 & \begin{tabular}{|l|}
5.250 .147 \\
\end{tabular} & $24,32 \%$ & $75,68 \%$ & 3.639 .413 & 100.000 & $0,00 \%$ & 47.900 & $-17,78 \%$ & 425.001 & $11,68 \%$ & $12,53 \%$ & - \\
\hline 2008 & 1.552 .953 & 4.255 .064 & \begin{tabular}{|l|}
5.808 .017 \\
\end{tabular} & $26,74 \%$ & $73,26 \%$ & 3.806 .091 & 100.000 & $0,00 \%$ & 32.384 & $-32,39 \%$ & 473.340 & $12,44 \%$ & $11,37 \%$ & - \\
\hline 2009 & 1.523 .864 & 4.430 .157 & 5.954 .021 & $25,59 \%$ & $74,41 \%$ & 3.764 .728 & 100.000 & $0,00 \%$ & 32.781 & $1,23 \%$ & 486.718 & $12,93 \%$ & $2,83 \%$ & \\
\hline 2010 & 1.643 .298 & 4.736 .001 & \begin{tabular}{|l|}
6.379 .299 \\
\end{tabular} & $25,76 \%$ & $74,24 \%$ & 3.987 .424 & 200.000 & $100,00 \%$ & 71.611 & $118,45 \%$ & 529.553 & $13,28 \%$ & $8,80 \%$ & \\
\hline 2011 & 1.773 .315 & 4.966 .374 & \begin{tabular}{|l|}
6.739 .689 \\
\end{tabular} & $26,31 \%$ & $73,69 \%$ & 4.151 .371 & 415.000 & $107,50 \%$ & 153.151 & $113,87 \%$ & 583.757 & $14,06 \%$ & $10,24 \%$ & 309.889 \\
\hline 2012 & 1.897 .376 & 5.140 .312 & \begin{tabular}{|l|}
7.037 .688 \\
\end{tabular} & $26,96 \%$ & $73,04 \%$ & 4.208 .086 & 502.500 & $21,08 \%$ & \begin{tabular}{|l|}
377.780 \\
\end{tabular} & $146,67 \%$ & 918.137 & $21,82 \%$ & $57,28 \%$ & 583.596 \\
\hline 2013 & $\begin{array}{l}1.932 .527 \\
\end{array}$ & $\begin{array}{l}5.373 .450 \\
\end{array}$ & \begin{tabular}{|l|}
7.305 .977 \\
\end{tabular} & $26,45 \%$ & $73,55 \%$ & \begin{tabular}{|l|}
4.374 .431 \\
\end{tabular} & 875.000 & $74,13 \%$ & 559.905 & $48,21 \%$ & \begin{tabular}{|l|l|}
1.168 .100 \\
\end{tabular} & $26,70 \%$ & $27,23 \%$ & 1.725 .369 \\
\hline 2014 & 1.961 .002 & 5.867 .011 & \begin{tabular}{|l|}
7.828 .013 \\
\end{tabular} & $25,05 \%$ & $74,95 \%$ & 4.664 .542 & 600.512 & $-31,37 \%$ & \begin{tabular}{|l|}
732.494 \\
\end{tabular} & $30,82 \%$ & \begin{tabular}{|l|}
1.910 .718 \\
\end{tabular} & $40,96 \%$ & $63,57 \%$ & 2.801 .042 \\
\hline 2015 & 1.952 .145 & 6.075 .152 & \begin{tabular}{|l|}
8.027 .297 \\
\end{tabular} & $24,32 \%$ & $75,68 \%$ & 4.809 .793 & 313.947 & $-47,72 \%$ & \begin{tabular}{|l|}
287.367 \\
\end{tabular} & $-60,77 \%$ & 2.185 .038 & $45,43 \%$ & $14,36 \%$ & 2.995 .270 \\
\hline 2016 & $\begin{array}{l}1.990 .078 \\
\end{array}$ & 6.058 .623 & \begin{tabular}{|l|}
8.048 .701 \\
\end{tabular} & $24,73 \%$ & $75,27 \%$ & 4.686 .806 & 325.279 & $3,61 \%$ & \begin{tabular}{|l|}
198.189 \\
\end{tabular} & $-31,03 \%$ & 2.441 .008 & $52,08 \%$ & $11,71 \%$ & 2.359 .266 \\
\hline 2017 & 2.045 .356 & 6.240 .982 & \begin{tabular}{|l|}
8.286 .338 \\
\end{tabular} & $24,68 \%$ & $75,32 \%$ & 4.649 .897 & 225.000 & $-30,83 \%$ & 175.925 & $-13,77 \%$ & \begin{tabular}{|l|}
2.765 .439 \\
\end{tabular} & $59,47 \%$ & $10,61 \%$ & 2.693 .934 \\
\hline 2018 & 2.077 .481 & 6.372 .040 & \begin{tabular}{|l|}
8.449 .521 \\
\end{tabular} & $24,59 \%$ & $75,41 \%$ & 4.489 .690 & 310.000 & $37,78 \%$ & 60.618 & $-34,61 \%$ & 2.554 .998 & $40,45 \%$ & $-34,32 \%$ & 1.808 .453 \\
\hline 2019 & & & & & & & & & & $-61,83 \%$ & \begin{tabular}{|l|}
690.220 \\
\end{tabular} & & & 690.220 \\
\hline
\end{tabular}

Fonte: Elaborada pelos autores $(2020)^{6}$.

De acordo com os dados da Tabela 1, na primeira década do Século XXI, enquanto a educação superior se expandia, o Fies seguia operando timidamente, até 2009 , quando foi amplamente reformulado através da Lei $n^{\circ}$ 12.202/2010 (BRASIL, 2010a). Em linhas gerais, o "Novo Fies", como foi batizado, passou a ser gerido pelo FNDE com a prerrogativa de administrar e operar os contratos ativos e passivos. Essas mudanças foram rápidas e fundamentais para os desdobramentos da política em análise.

A evolução do Fies pode ser dividida em quatro ciclos - até 2009; entre 2010 e 2014; entre 2015 e 2018; e até 2022. Até 2009, o Fies esteve à procura de espaço e afirmação no cenário educacional, com poucos contratos assinados e permanentes movimentos do agente operador (CEF) a fim de expandir sua divulgação e acesso, conforme descrito nos Relatórios de Gestão do Fies. Entre 1999 e 2010, mesmo ofertando crescente número de vagas, as

6 Matrículas da Educação Superior: (INEP, 1999a; 1999b; 2007; 2008; 2009; 2010; 2011; 2012; 2013; 2014; 2015; 2016; 2000b; 2017; 2018; 2000a; 2001; 2002; 2003; 2004; 2005; 2006). Vagas e Contratos Fies Relatórios de Gestão: (BRASIL, 2008; 2009b; 2010c; 2011c; 2012; 2013; 2014b; 2015b; 2016a; 2017c; BRASIL; CEF, 2001; 2002; BRASIL, 1999g; CEF, 2000; 2003; 2004; 2005; 2006; 2007), (FNDE, 2018c; 2018d; 2019e; 2019f). Contratos Ativos (2007): arbitrado pelo autor, sobre a média de contratos ativos entre 2006 e 2008, respectivamente, pois não foi localizado o total exato em qualquer fonte utilizada para os demais registros. Contratos novos (2017 e 2018) (FNDE, 2018i). Contratos ativos (2017) (FNDE, 2018e). Microdados, para os anos 2011 a 2019: (FNDE, 2011a; 2011b; 2012b; 2012a; 2013b; 2013a; 2014b; 2014a; 2015a; 2015b; 2016b; 2016a; 2017b; 2017a; 2018d; 2018c; 2019e; 2019f). 
adesões sempre frustravam as campanhas, o que obrigaria o MEC a flexibilizar o sistema. Os dois ciclos seguintes serão comentados na sequência.

O "Novo Fies" foi veículo de um movimento fundamental: a operação de fato do Fundo de Garantia de Operações de Crédito Educativo (FGEDUC), que seria administrado pelo Banco do Brasil $(\mathrm{BB})^{7,8}$. O desdobramento específico do "Novo Fies" para o nosso interesse teria início com a MP $n^{\circ} 501 / 2010$ (BRASIL, 2010b), convertida na Lei $n^{\circ} 12.385 / 2011$ (BRASIL, 2011a). Essa mudança representou uma inflexão no funcionamento do Fies: até então, um dos maiores entraves era a obrigatoriedade de fiador para a contratação do Fies junto aos agentes bancários, o que se tornou inócuo a partir da assunção do FGEDUC, que passou a ser um "seguro-fiança" a um público específico, selando o futuro do Fies, ao permitir a expansão inusitada da política de acesso à educação superior privada com aval do Estado, na qual o FGEDUC tornou-se o "garantidor do risco" de inadimplemento (BRASIL, 2011b).

Outra ação criada, que o MEC chamaria de "fiança solidária", permitia que um grupo de amigos ou familiares, ou mesmo colegas do aluno, fossem fiadores uns dos outros, ainda que não tivessem como afiançar bens ou direitos que garantissem o respectivo compromisso. Aqui, também cabe especial atenção no que tange ao FGEDUC: ainda que estivesse operando desde 2011, só obrigou as entidades mantenedoras a aderirem ao Fundo como partícipes solidárias a partir das disposições da Portaria MEC n³/2014 (BRASIL, 2014a), ou seja, nesse interstício de três anos, o único risco era de seus agentes operadores, o BB e o FNDE.

Expostas as regras gerais do "Novo Fies", observamos uma explosão de adesões, passando de 529.533 contratos, em 2010, para 1.910.714, em 2014. A despesa pública acompanhou o crescimento exponencial dos beneficiários. Entre 1999 e 2010, os recursos do Fies já vinham crescendo, embora com oscilações positivas ou negativas. A partir de então, sua rubrica passa a flutuar a percentuais que superam os $100 \%$ ao ano entre 2010 e 2012 , atingindo o ápice em 2016, quando $\mathrm{R} \$ 32,9$ bilhões foram executados (em valores constantes). Contudo, desde 2015 novas adesões decrescem a cada exercício, fruto das políticas que novamente repaginariam o Fies (Tabela 1).

O ano de 2014 foi marcado pela realização de uma Copa no Brasil e uma disputa eleitoral nunca antes tão polarizada, o que terminava regulando o próprio mercado. De um lado, a Presidenta Dilma Rousseff concorria à reeleição; representando a alternativa à coalizão liderada pelo PT há 12 anos, estava o então Senador Aécio Neves. Se as intenções de voto em Dilma Rousseff subiam, os "papéis Dilma" - como eram chamadas as ações das empresas beneficiadas - eram valorizados, em uma lógica que atribuía sua vitória à

7 Esse dispositivo financeiro já estava previsto especificamente na Lei $n^{\circ} 12.087 / 2009$, que autorizava a União a participar, de acordo com o art. $7^{\circ}$, "no limite global de até $\mathrm{R} \$ 4.000 .000 .000,00$ (quatro bilhões de reais), de fundos que, atendidos os requisitos fixados nesta Lei, tenham por finalidade, alternativa ou cumulativamente [...] garantir diretamente o risco em operações de crédito educativo, no âmbito de programas ou instituições oficiais, na forma prevista nos estatutos dos respectivos fundos" (inciso III). (BRASIL, 2009a). De acordo com o Plano Trienal 2020-2022 do Fies, "o Ministério da Educação deverá apresentar, no exercício de 2020, proposta de Projeto de Lei ou de Medida Provisória com vistas a ampliar o limite estabelecido no artigo $6^{\circ}-\mathrm{G}$ da Lei 10.260/2001, ficando a União autorizada a participar no limite global de até $R \$ 4.500 .000 .000,00$ (quatro bilhões, quinhentos milhões de reais) no Fundo Garantidor do Fies, com vistas à realização de aportes adicionais de $\mathrm{R} \$ 500$ milhões/ano no período de 2024 a 2026" (FNDE, 2019a, p. 16).

8 Em 11 de julho de 2018, o FGEDUC foi reformulado, passando a chamar-se Fundo Garantidor do Fundo de Financiamento Estudantil (FG-Fies), e voltou a ser administrado pela CEF (CEF, 2020). 
manutenção das regras vigentes no Fies e, por conseguinte, o enriquecimento que a política proporcionava aos fornecedores de serviços correlatos (BURGARELLI, 2017, p. 45).

Concluído o certame, Dilma Rousseff manteve-se no exercício do cargo, mas o anúncio de uma nova equipe mudaria os rumos do Fies e de outras políticas sociais. Joaquim Levy assumiu a pasta da Fazenda e, imediatamente após a sua nomeação, anunciou um pacote de medidas que incluía a alta de impostos e diversos contingenciamentos, sob o argumento de reequilibrar o orçamento e "aumentar a confiança na economia de forma a alcançarmos com menor sacrifício possível a retomada do caminho do crescimento" (CRUZ, 2015). Os ajustes fiscais do período não excluiriam o Fies, mas o que terminou por eclipsar seu crescimento foi a combinação de uma crise econômica que se aproximava e uma matemática incoerente: embora os investimentos no Fies subissem exponencialmente, o cabalístico número de 10 milhões de estudantes matriculados na educação superior, profetizado por Fernando Haddad, Ministro da Educação em 2010, não se confirmava.

Novos contratos eram assinados, mas as matrículas presenciais gerais em instituições de educação superior privadas seguiam seu crescimento quase vegetativo: em 2010, o Fies financiava $8,3 \%$ desses registros; em 2016, 30,33\% (Tabela 1). Sabendo que os contratos só podem ser analisados sob a ótica de matrículas presenciais, o percentual é mais alarmante: $37,24 \%$ dos alunos matriculados em 2016 possuíam contrato ativo. Diante disso, como o Fies poderia ter multiplicado seu número de contratos em 409,86\% entre 2010 e 2017, e as matrículas privadas evoluírem apenas $17,54 \%$ no mesmo período? A combinação supracitada - crise econômica e matemática que não fecha -, submeteu o Fies à investigação da mídia, da academia e de órgãos públicos ligados ao orçamento, que apontavam um futuro dramático de manutenção da política, sobre o que esboçamos alguns termos da discussão.

\section{O Fies sob análise de especialistas}

Sguissardi (2015, p. 870) denuncia como o setor educacional tornou-se o negócio mais atrativo na Bolsa de Valores de São Paulo (BOVESPA) entre 2012 e $2014^{9}$. O autor descreve o período histórico em que ocorre essa inversão:

[...] a entrada do setor financeiro na educação superior do Brasil ocorre, portanto, com a associação da Kroton (então Pitágoras), em 2001, com o Grupo Apollo International, seguida pela compra da Universidade Anhembi-Morumbi pela Laureate, em 2006, e, especialmente, pela abertura de capital das empresas Anhanguera, Kroton, Estácio e SEB em 2007 (SGUISSARDI, 2015, p. 872).

Silva e Soares (2019, p. 14) revelam que, até 2014, as empresas educacionais eram as mais atraentes na BM\&F Bovespa, "porque tinham um negócio em franca expansão, financiado em boa parte pelo governo federal". O ingresso de Levy teria impacto imediato no mercado educacional: no intervalo entre novembro de 2014 e março de 2015, os papéis da Kroton desvalorizaram 41\%, e, os da Anima Educação, 54\% (BURGARELLI, 2017).

Em Boletim Legislativo do Senado, Marcos Mendes, Consultor Legislativo da Casa, fez uma análise das despesas federais em educação no período entre 2004 e 2014 e descreveu

9 Sguissardi (2015, p. 870) descreve detalhadamente como a Bolsa de Valores de São Paulo comportou-se à época: "enquanto o Ibovespa (índice do total de cerca de 350 empresas) teve uma redução de 3,67\%; a Vale (VALE5), redução de 13,48\%; e a Petrobras (PETR4), valorização de 9,32\% de suas ações; a Kroton (KROT3) teve uma valorização de $314 \%$ e a Estácio (ESTC3), $240,97 \%$ de suas respectivas ações". 
que a pasta teria sido a que mais cresceu no período: com desembolso inicial de $4 \%$ da receita líquida do Tesouro, passou para 9,3\% em 2014. Ao separar a despesa de pessoal das demais, o autor descreve mecanismos financeiros e orçamentários do Fies, sublinhando o fato de o Programa ter se tornado a maior despesa da União em educação, excluídos os gastos com pessoal, consumindo $14,61 \%$ da despesa federal em educação, conforme a Tabela 2 , extraída dos seus achados.

Tabela 2 - Despesas do governo federal em educação, em pessoal, em encargos sociais, e em grupos de ações nos demais grupos de natureza da despesa entre 2004 e 2014, em milhões de R\$ de 2014

\begin{tabular}{|c|c|c|c|c|}
\hline & 2004 & 2014 & $\begin{array}{c}\text { Participação } \\
\text { no total em } \\
2014(\%)\end{array}$ & $\begin{array}{c}\text { Var. } \\
\text { Real } \\
2004- \\
2014 \\
\end{array}$ \\
\hline Pessoal e encargos sociais & 11.890 & 29.723 & 0,32 & $150 \%$ \\
\hline Concessão de financiamento estudantil - FIES e antecessores & 1.138 & 13.769 & 0,15 & $1110 \%$ \\
\hline Complementação da União ao FUNDEF/FUNDEB & 832 & 10.862 & 0,12 & $1205 \%$ \\
\hline Funcionamento e Investim. em inst. federais de ensino superior & 2.546 & 8.790 & 0,09 & $245 \%$ \\
\hline Educação profissional e tecnológica & 436 & 7.127 & 0,08 & $1533 \%$ \\
\hline Funcionamento e investimentos na educação básica & 2.402 & 6.999 & 0,07 & $191 \%$ \\
\hline Bolsas de estudo no país e no exterior - ensino superior & 775 & 5.132 & 0,05 & $562 \%$ \\
\hline Apoio à alimentação escolar na educação básica & 1.740 & 3.702 & 0,04 & $113 \%$ \\
\hline Dinheiro direto na escola para a educação básica & 594 & 2.119 & 0,02 & $257 \%$ \\
\hline Apoio ao transporte escolar na educação básica & 444 & 977 & 0,01 & $120 \%$ \\
\hline Exames, avaliações, estatísticas e censos & 192 & 815 & 0,01 & $325 \%$ \\
\hline Outros & 1.464 & 4.185 & 0,04 & $186 \%$ \\
\hline Total & 24.453 & 94.201 & $\mathbf{1 , 0 0}$ & $285 \%$ \\
\hline Total sem FIES & 23.315 & 80.431 & & $245 \%$ \\
\hline
\end{tabular}

Fonte: Mendes (2015, p. 4).

Cabe observar que o Fies não seria uma despesa de fato, mas uma "inversão financeira", por se tratar de um empréstimo a ser quitado após a conclusão do curso $^{10}$. Contudo, a forma como os financiamentos foram contraídos durante os últimos anos de sua análise, permitiu ao autor identificar que "[...] os juros reais cobrados nessa linha de financiamento são negativos, e não há no orçamento qualquer rubrica para registrar os subsídios creditícios daí decorrentes (o que acaba por subestimar a despesa)", além da importante possibilidade de inadimplência que os mecanismos utilizados permitiam (MENDES, 2015, p. 5).

Como política social, Mendes compara os investimentos realizados no Fies com a complementação da União ao Fundo de Manutenção e Desenvolvimento da Educação Básica e de Valorização dos Profissionais da Educação (Fundeb), com o objetivo de complementar recursos de estados e municípios. Sua análise revela o que já estava timidamente exposto na Tabela 2: o Fies já representava uma despesa maior que a complementação ao Fundeb em 2014, conforme exposto na Tabela 3.

10 Uma ressalva: o início da quitação pode ocorrer antes da conclusão do curso, o que depende do número de semestres contratado na formalização inicial e a formatura do aluno. 
Tabela 3 - Despesas com o Fies e complementação da União ao Fundeb entre 2007 e 2014, em milhões de $\mathbf{R}$ de 2014

\begin{tabular}{|c|c|c|c|c|c|c|}
\hline & \multicolumn{3}{|c|}{ FIES } & \multicolumn{3}{|c|}{$\begin{array}{c}\text { Complementação da União ao } \\
\text { FUNDEF/FUNDEB }\end{array}$} \\
\hline & 2014 & \begin{tabular}{c|}
$\%$ \\
do \\
PIB
\end{tabular} & $\begin{array}{l}\text { \% Receita } \\
\text { Líquida }\end{array}$ & 2014 & $\begin{array}{c}\% \\
\text { do } \\
\text { PIB }\end{array}$ & $\begin{array}{l}\text { \% Receita } \\
\text { Líquida }\end{array}$ \\
\hline 2007 & 1.149 & 0,03 & 0,15 & 2.984 & 0,07 & 0,39 \\
\hline 2008 & 1.241 & 0,03 & 0,15 & 4.438 & 0,1 & 0,54 \\
\hline 2009 & 1.302 & 0,03 & 0,16 & 6.764 & 0,15 & 0,83 \\
\hline 2010 & 1.211 & 0,02 & 0,12 & 7.421 & 0,15 & 0,75 \\
\hline 2011 & 2.247 & 0,04 & 0,23 & 10.553 & 0,2 & 1,08 \\
\hline 2012 & 5.342 & 0,1 & 0,53 & 11.789 & 0,22 & 1,18 \\
\hline 2013 & 8.189 & 0,15 & 0,78 & 10.604 & 0,19 & 1 \\
\hline 2014 & 13.769 & 0,25 & 1,36 & 10.862 & 0,2 & 1,07 \\
\hline
\end{tabular}

Nota: O Fundeb passou a vigorar em 2007 e sua implantação plena ocorreu em 2010. Fonte: Mendes (2015, p. 6).

A partir dos dados da Tabela 3, Mendes pondera que a multiplicação de alunos e escolas financiadas pelo Fies também promoveu a transformação destas em "potências empresariais", sem que tenham sido respondidas questões relacionadas à qualidade dos cursos ofertados ou ao desempenho acadêmico dos estudantes. Nesse sentido, é possível perceber como o período 2004-2014, analisado por Mendes, exibe a importante valorização do financiamento estudantil ante a principal ação de assistência financeira da União à educação básica. $O$ contraste dá relevo ao significativo aumento dos recursos do FIES, como também ao fato de que a complementação da União ao Fundeb manteve-se no nível da aplicação mínima obrigatória. Uma abordagem mais refinada, e que não será desenvolvida neste estudo, exigiria diferenciar os custos do ensino da educação básica e da superior, elemento indispensável para comparar despesas com os dois níveis.

Entre abril e junho de 2015, dois estudos assinados pela Secretaria do Tesouro Nacional (STN) também analisaram o Fies, sinalizando a sua reformulação (BRASIL, 2015c; 2015d). No primeiro, são tratados problemas relacionados à renda dos beneficiários do Programa, o quanto ele tem considerado as desigualdades regionais e como tem sido mensurada a qualidade do ensino, tudo isso, é claro, sob a luz do período em tela (2015, ou seja, período de recessão). Nessa análise, o Fies não estaria cumprindo, da forma como vinha operando, o papel de uma política educacional, mas, sim, prestando-se a uma "mera transferência de renda".

Ao confirmar que tanto o Fies quanto o Prouni impactaram famílias com faixas de renda familiar bruta de até quatro salários mínimos (s.m.), o estudo reconhece que a expansão das universidades públicas, somada às políticas de cotas, podem ter contribuído para uma diminuição da demanda a políticas como aquelas: "[...] o efeito do Fies e do Prouni teria sido provavelmente maior caso não tivesse ocorrido a referida expansão das universidades públicas e a adoção da política de quotas" (BRASIL, 2015c, p. 13). Entre as recomendações da equipe, destaca-se a de maior focalização do Programa, a limitação da renda familiar a cinco s.m., ou 1,25 s.m. per capita, contra os 20 s.m. que eram praticados até então, além de considerar critérios regionais, a exigência de Conceito Preliminar de Curso (CPC) 4 e 5, e 
Reformulações e Implementação do Fies (1999-2020)

estabelecer critérios meritocráticos, a exemplo do desempenho no Exame Nacional do Ensino Médio (Enem).

Em boletim publicado no mês seguinte, é discutida a sustentabilidade do Programa, com base nas características das taxas de juros praticadas, na coparticipação das famílias e na observância à Resolução $n^{\circ} 4.432 / 2015$ (BRASIL, 2015a); esta última restabeleceu a cobrança da taxa efetiva de juros de $6,5 \%$ a.a. para os contratos assinados a partir de então: "[...] para não retirar o seu caráter social, uma proposta seria instituir uma taxa de juros crescente com as faixas de renda da elegibilidade, de modo que a taxa média estivesse relacionada ao risco e a inadimplência global do Fies" (BRASIL, 2015d, p. 2). Interessante observar as recomendações relacionadas ao orçamento familiar: para os autores, o percentual de financiamento suportável deveria "[...] estabelecer mecanismos de mercado que ampliem a sensibilidade dos alunos em relação ao preço das mensalidades, extinguindo o financiamento integral" (BRASIL, 2015d, p. 3).

Para os analistas, a forma como o Fies era conduzido terminava por incentivar a participação de sujeitos que podiam custear seus estudos, mas o contratavam justamente pela taxa de juros subsidiada e a facilidade de pagamento proporcionada, num evidente fenômeno de crowding-out, que descreveremos a seguir.

\section{Fies como ferramenta de crowding-out}

Aqui, mais um elemento entra em discussão: o subsídio implícito do Programa. Entendese por subsídio implícito, no estudo em tela, a prática de taxas de juros reduzidas pelos cofres públicos, em que o custo seria a diferença entre a taxa paga na emissão dos CFT-Es e a respectiva taxa de juros do Fies, o que, conforme descrito pelos analistas, "[...] representa um impacto direto sobre o Resultado Nominal e, portanto, sobre a relação dívida bruta/PIB" (BRASIL, 2015d, p. 4). Nascimento e Longo (2016, p. 15-18) descrevem esse subsídio implícito como a "[...] parcela do empréstimo que nunca será efetivamente paga pelo beneficiário do Fies - ou quantos reais, aproximadamente, terão sido arcados pelo contribuinte para cada cem reais do valor presente do saldo devedor sobre o qual incidiram taxas de juros subsidiadas por toda a duração do financiamento". Para os autores, na política de juros aplicada entre 2010 e 2014 "apenas 53\% do valor original do financiamento era reembolsado - os outros $47 \%$ eram, por conseguinte, arcados pelo contribuinte, mesmo que nenhuma parcela deixasse de ser paga pelo mutuário", e que, mesmo após as mudanças realizadas em 2015 "[...] que elevaram a taxa de juros para $6,5 \%$ a.a. e reduziram em doze meses o limite do prazo de amortização, a taxa de reembolso aumentou para $73 \%$ e o subsídio reduziu de $47 \%$ para $27 \%$ do valor do financiamento". A evolução desse fenômeno é exibida no Gráfico 1, em pontos percentuais. 


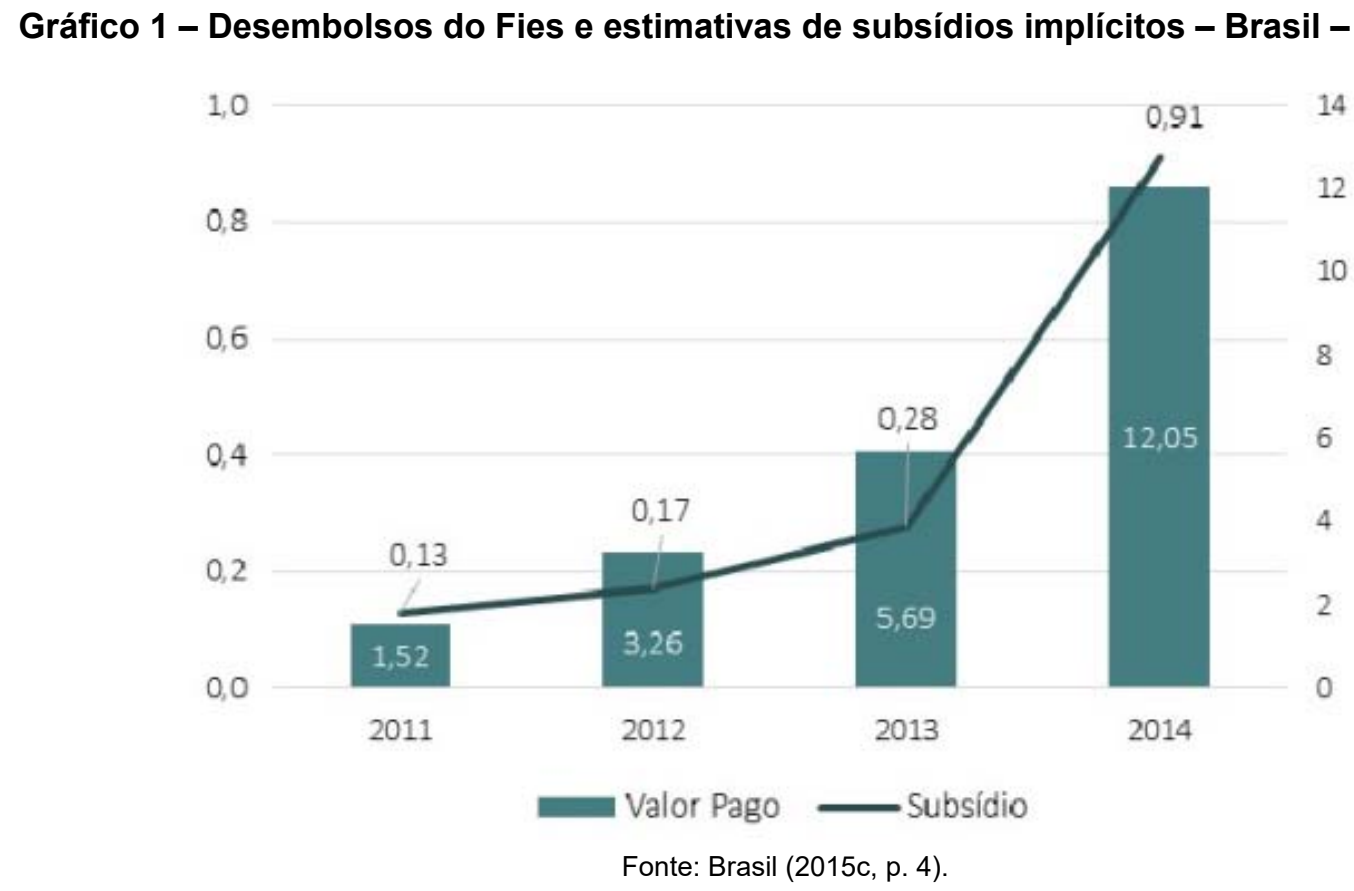

Cruzando o estudo produzido pela STN (BRASIL, 2015c, p. 4-5) com o de Nascimento e Longo (2016, p. 15-18), podemos interpretar o Gráfico 1, no qual aparece que, entre 2011 e 2014 , o subsídio implícito aumenta de $13 \%$ para $91 \%$ dos contratos assinados. Para mitigar esse fenômeno, os analistas da STN propõem um escalonamento dos juros: "certos indivíduos pagam valor mais alto por um serviço a fim de compensar o valor mais baixo cobrado daqueles que se encontram em situação mais vulnerável". Entre as conclusões da STN, são propostos o realinhamento das condições de financiamento, já em curso através das mudanças recémlançadas, um novo modelo de coparticipação, que estabeleça "uma alíquota fixa de comprometimento de renda per capita da família", e a adoção de uma maior previsibilidade de oferta de vagas.

\section{Números do Fies}

Em junho de 2017, o MF também apresentou novo relatório sobre a situação do Fies (BRASIL, 2017d) ${ }^{11}$, tratando do mascaramento dos custos reais do Programa, dispostos nas Tabelas 4, 5, 6 e $7^{12}$.

11 Nesse momento, o discurso dominante já era de desmonte e descrédito ao Programa, vide o título do estudo Fundo de Financiamento Estudantil: ausência de sustentabilidade fiscal e suas causas.

12 Valores atualizados e confirmados através da triangulação de dados dos Relatórios Anuais de Gestão do Fies, dos Relatórios Anuais de Gestão dos Operadores dos Fundos Garantidores de Crédito FGEDUC e FG-Fies BB e CEF, Portal da Transparência, Relatórios de Emissões de Títulos da Dívida Pública da STN e Sistema Siga Brasil, do Senado. 
Tabela 4 - Execução financeira anual do Fies, por emissão, recompra e repasse de CFT-E Brasil - 2010-2019, em milhões de R\$

\begin{tabular}{|l|r|r|r|}
\hline Ano & $\begin{array}{c}\text { Emissão Primária de } \\
\text { CFT-E }\end{array}$ & $\begin{array}{c}\text { Recompra de } \\
\text { CFT-E }\end{array}$ & \multicolumn{1}{c|}{$\begin{array}{c}\text { Repasse de } \\
\text { CFT-E }\end{array}$} \\
\hline 2010 & 995,69 & 107,48 & 410,56 \\
\hline 2011 & $2.014,56$ & 584,75 & $2.031,69$ \\
\hline 2012 & $1.995,57$ & $3.032,46$ & $5.782,56$ \\
\hline 2013 & $3.820,48$ & $7.272,52$ & $11.230,84$ \\
\hline 2014 & $5.257,43$ & $11.176,78$ & $17.804,33$ \\
\hline 2015 & $4.846,01$ & $10.773,81$ & $15.670,38$ \\
\hline 2016 & $5.189,56$ & $13.726,29$ & $18.063,63$ \\
\hline 2017 & $6.489,54$ & $13.538,40$ & $19.543,38$ \\
\hline 2018 & 264,81 & $10.530,30$ & $15.035,65$ \\
\hline 2019 & $2.020,60$ & $4.711,61$ & $6.959,94$ \\
\hline$\sum$ & $\mathbf{3 2 . 8 9 4 , 2 6}$ & $\mathbf{7 5 . 4 5 4 , 3 9}$ & $\mathbf{1 1 2 . 5 3 2 , 9 5}$ \\
\hline
\end{tabular}

Fonte: Elaborada pelos autores (2020), a partir de BB (2020); Brasil (2020); CEF (2020); FNDE (2020b; 2020c). Vide Nota ${ }^{13}$.

A Tabela 4 nos permite concluir com bastante facilidade que, nos dez anos, foram emitidos $R \$ 32,8$ bilhões de títulos CFT-E, recomprados $R \$ 75,4$ bilhões e repassados a instituições superiores privadas $\mathrm{R} \$ 112,5$ bilhões, com títulos de vencimento de até 40 anos, desde a data de emissão. Outro aspecto que merece destaque, no que se refere a essa transação, são os "[...] atrasos no repasse dos recursos pelo governo federal, ou seja, não cumprimento do calendário estabelecido para a recompra de títulos emitidos em favor das instituições" (FILHO; CHAVES, 2017, p. 89). Segundo os autores:

\begin{abstract}
Esses atrasos no repasse de recursos, por meio da recompra dos títulos em favor das instituições privado-mercantis, decorrem da necessidade de aprovação de créditos suplementares na Lei Orçamentária Anual. Com a expansão no número de contratos e na demanda por mais recursos financeiros, o Fies passou a exigir mais recursos do orçamento, com aprovação de créditos suplementares, [...], os quais exigem aprovação prévia do Congresso Nacional, gerando atrasos nos repasses às instituições de ensino. $\mathrm{A}$ ampla expansão do Fies, no período de 2010 a 2015, além de gerar receitas operacionais para as instituições de ensino, trouxe obrigações ao governo federal, com o endividamento em decorrência de atrasos nos repasses às instituições, aumentando os créditos dessas entidades junto ao governo federal. Trata-se também de uma forma de endividamento estatal, tendo em vista que os valores a receber pelos grupos educacionais constituem obrigações financeiras pelo Estado (FILHO; CHAVES, 2019, p. 89).
\end{abstract}

Para os autores, essa combinação de fatores termina aumentando o endividamento público, mas, sobretudo, acrescenta duas preocupações: a primeira, de que o processo de expansão dos grupos educacionais, por meio do Fies, ocorre através do endividamento das famílias, e, por conseguinte, citando Godeiro e Gurgel (2015, p. 33 apud SANTOS FILHO; CHAVES, 2017, p. 92) "[...] que o mais desolador de tudo é saber que, para esses [...]

13 Emissão primária de CFT-E: STN (2020). Recompra de CFT-E: (FNDE, 2010a; 2011c; 2011d; 2012d; 2012c; 2013d; 2013c; 2014d; 2014c; 2015d; 2015c; 2016d; 2016c; 2017c; 2018g; 2018f; 2019g; 2019h). Repasse de CFT-E: (FNDE, 2010b; 2011e; 2012e; 2013e; 2014e; 2015e; 2016e; 2017d; 2018h; 2019r; 2019j; 2019k; 2019l; 2019m; 2019n; 2019o; 2019p; 2019q; 2019i) 
'beneficiários' do Fies, além da dívida, com data marcada para ser paga, a única certeza possível é a de que esse diploma na mão não é a garantia de emprego".

Tabela 5 - Execução financeira anual do FIES, por repasse ao FGEDUC/FG-FIES ao CCG Brasil - 2010-2019, em milhões de R\$

\begin{tabular}{|l|r|}
\hline \multicolumn{1}{c|}{ Ano } & \multicolumn{2}{|c}{$\begin{array}{r}\text { Repasse ao FGEDUC } \\
\text { ou FG-FIES } \rightarrow \text { CCG }\end{array}$} \\
\hline 2010 & 0,00 \\
\hline 2011 & 1,44 \\
\hline 2012 & 9,83 \\
\hline 2013 & 263,24 \\
\hline 2014 & 745,84 \\
\hline 2015 & 644,50 \\
\hline 2016 & 819,14 \\
\hline 2017 & 917,57 \\
\hline 2018 & 821,51 \\
\hline 2019 & 649,45 \\
\hline & $\mathbf{4 . 8 7 2 , 5 2}$ \\
\hline
\end{tabular}

Fonte: Elaborada pelos autores (2020), com base em (BRASIL, 2020b; 2014b; 2016a; 2017c; 2017d; FNDE, 2019a).

Tabela 6 - Aportes ao FGEDUC e FG-Fies e despesas administrativas de manutenção e administração do Fies - Brasil - 2010-2022, em milhões de R\$

\begin{tabular}{l|r|r}
\hline \multicolumn{1}{c|}{ Ano } & \multicolumn{1}{c|}{$\begin{array}{c}\text { Aportes no } \\
\text { FGEDUC/FG-FIES }\end{array}$} & $\begin{array}{c}\text { Despes as } \\
\text { Adminis trativas }\end{array}$ \\
\hline 2010 & 0,00 & 103,73 \\
\hline 2011 & 148,48 & 3,47 \\
\hline 2012 & 200,06 & 171,26 \\
\hline 2013 & 0,00 & 137,22 \\
\hline 2014 & $1.674,33$ & 0,00 \\
\hline 2015 & 549,50 & 669,93 \\
\hline 2016 & 628,20 & 746,96 \\
\hline 2017 & 633,97 & 684,57 \\
\hline 2018 & 521,55 & 440,79 \\
\hline 2019 & 500,00 & 451,06 \\
\hline 2020 & 499,78 & 855,56 \\
\hline 2021 & 500,00 & 854,60 \\
\hline 2022 & 500,00 & 859,60 \\
\hline & $\mathbf{6 . 3 5 5 , 8 7}$ & $\mathbf{5 . 9 7 8 , 7 6}$ \\
\hline
\end{tabular}

Fonte: Elaborada pelos autores (2020), a partir de BB (2020); Brasil (2018e; 2020); FNDE (2019g, p. 18); MEC (2010c; 2011b; 2012; 2013b; 2014c; 2015d; 2016; 2019b) ${ }^{14}$.

A Tabela 5 apresenta os repasses realizados ao Fundo Garantidor do Fies. A Tabela 6 exibe as despesas administrativas para a gestão do Programa junto aos operadores

14 Aportes no FG-EDUC/FG-FIES: (BB, 2011; 2012; 2013; 2014; 2015; 2018b; 2018a; BRASIL, 2020a; 2020c; 2010d; 2014c; 2015e; 2016b; FNDE, 2019a). Despesas administrativas: (BRASIL, 2020d; 2010c; 2011c; 2012; 2013; 2014b; FNDE, 2019a). 
financeiros, estipulada pela Lei do Fies em $2 \%$ a.a. sobre o saldo devedor dos financiamentos concedidos e ponderados pela taxa de adimplência, bem como os custos de integralização das cotas do FGEDUC/FG-Fies. Nesse estrato observamos o salto de $2.300 \%$ das despesas administrativas para a manutenção do Programa entre 2011 e 2016 e o aporte ao FGEDUC em 2014, R\$ 1,67 bilhão (em valores constantes).

Tabela 7 - Subsídios implícitos do Fies - Brasil - 2010-2022, em milhões de R\$

\begin{tabular}{l|r}
\hline \multicolumn{1}{c|}{ Ano } & \multicolumn{1}{c}{$\begin{array}{c}\text { Subsídio } \\
\text { Implícito }\end{array}$} \\
\hline 2010 & $1.641,86$ \\
\hline 2011 & 25,15 \\
\hline 2012 & 768,13 \\
\hline 2013 & 823,77 \\
\hline 2014 & $2.410,94$ \\
\hline 2015 & $7.881,25$ \\
\hline 2016 & $12.739,30$ \\
\hline 2017 & $8.206,77$ \\
\hline 2018 & $4.978,92$ \\
\hline 2019 & $3.948,00$ \\
\hline 2020 & $4.041,00$ \\
\hline 2021 & $5.195,00$ \\
\hline 2022 & $6.868,00$ \\
\hline & $\mathbf{5 9 . 5 2 8 , 1 1}$ \\
\hline
\end{tabular}

Fonte: 2003 a 2018 (BRASIL, 2020e). 2020 a 2022 (FNDE, 2019a).

A Tabela 7, combinada ao Gráfico 1, exibe o aumento exponencial do subsídio implícito do Fies entre 2014 e 2016 e revela o emprego de despesa pública para a manutenção dos contratos firmados no período. A Tabela 8 , que será confrontada na sequência pela Tabela 9 , extraída do Projeto de Lei de Diretrizes Orçamentárias (PLDO) 2018 (BRASIL, 2018e), permitir-nos-á uma visão consolidada e uma reflexão do Fies sobre os demais custos federais.

Tabela 8 - Custo efetivo do Fies - Brasil - 2010-2022, em milhões de R\$

\begin{tabular}{|c|c|c|c|c|c|c|c|c|}
\hline Ano & $\begin{array}{c}\text { Emissão Primária de } \\
\text { CFT-E (A) }\end{array}$ & $\begin{array}{c}\text { Recompra de } \\
\text { CFT-E (B) }\end{array}$ & $\begin{array}{c}\text { Repasse ao FGEDUC } \\
\text { ou FG-FIES } \rightarrow \text { CCG } \\
\text { ('C) }\end{array}$ & \begin{tabular}{|c|} 
Aportes no \\
FGEDUC/FG-FIES \\
(D) \\
\end{tabular} & \begin{tabular}{|c|} 
Despesas \\
Administrativas \\
(E)
\end{tabular} & $\begin{array}{c}\text { Subsídio } \\
\text { Implícito (F) }\end{array}$ & $\begin{array}{l}\text { Repasse de } \\
\text { CFT-E (G) }\end{array}$ & $\begin{array}{c}\text { Custo Efetivo } \\
\text { do Fies } \\
(\mathbf{C}+\mathbf{D}+\mathbf{E}+\mathbf{F}+\mathbf{G}) \\
\end{array}$ \\
\hline 2010 & \begin{tabular}{l|l}
995,69 \\
\end{tabular} & 107,48 & 0,00 & $\begin{array}{r}0,00 \\
\end{array}$ & \begin{tabular}{|r|}
103,73 \\
\end{tabular} & $1.641,86$ & 410,56 & $2.156,16$ \\
\hline 2011 & $2.014,56$ & 584,75 & 1,44 & 148,48 & 3,47 & 25,15 & $2.031,69$ & $2.210,23$ \\
\hline 2012 & $1.995,57$ & $3.032,46$ & 9,83 & 200,06 & 171,26 & 768,13 & $5.782,56$ & $6.931,84$ \\
\hline 2013 & $3.820,48$ & $7.272,52$ & 263,24 & 0,00 & 137,22 & 823,77 & $11.230,84$ & $12.455,08$ \\
\hline 2014 & $\begin{array}{l}5.257,43 \\
\end{array}$ & $11.176,78$ & 745,84 & $1.674,33$ & 0,00 & $2.410,94$ & $17.804,33$ & $22.635,44$ \\
\hline 2015 & $\begin{array}{l}4.846,01 \\
\end{array}$ & $\begin{array}{l}10.773,81 \\
\end{array}$ & 644,50 & 549,50 & 669,93 & $7.881,25$ & $\begin{array}{l}15.670,38 \\
\end{array}$ & $25.415,57$ \\
\hline 2016 & $5.189,56$ & $13.726,29$ & 819,14 & 628,20 & 746,96 & $12.739,30$ & $18.063,63$ & $32.997,24$ \\
\hline 2017 & $6.489,54$ & $13.538,40$ & 917,57 & 633,97 & 684,57 & $8.206,77$ & $19.543,38$ & $29.986,26$ \\
\hline 2018 & 264,81 & $10.530,30$ & 821,51 & 521,55 & 440,79 & $4.978,92$ & $15.035,65$ & $21.798,41$ \\
\hline 2019 & $2.020,60$ & $4.711,61$ & 649,45 & 500,00 & 451,06 & $3.948,00$ & $6.959,94$ & $12.508,45$ \\
\hline 2020 & & & & 499,78 & 855,56 & $4.041,00$ & & $5.396,34$ \\
\hline 2021 & & & & 500,00 & 854,60 & $5.195,00$ & & $6.549,60$ \\
\hline \multirow[t]{2}{*}{2022} & & & & 500,00 & 859,60 & $6.868,00$ & & $8.227,60$ \\
\hline & $32.894,26$ & $75.454,39$ & $4.872,52$ & $6.355,87$ & $5.978,76$ & $59.528,11$ & $112.532,95$ & $169.094,68$ \\
\hline
\end{tabular}


Tabela 9 - Composição da despesa primária da União, em milhões de R \$ - Brasil - 2010-2017

\begin{tabular}{|c|c|c|c|c|c|c|}
\hline \multirow[b]{2}{*}{ Despesas Primárias } & \multicolumn{2}{|c|}{$49,7 \%$} & \multicolumn{2}{|c|}{$53,7 \%$} & \multicolumn{2}{|c|}{$57,0 \%$} \\
\hline & 2010 & $\%$ & 2016 & $\%$ & 2017 & $\%$ \\
\hline Beneficios Previdenciários -Urbano & $1 \overline{198.769}$ & $2 \overline{8}, 1 \% !$ & $1 \overline{396.56 \overline{1}}$ & $\overline{31,9 \overline{\%} !}$ & $1 \overline{435.065}$ & $3 \overline{3}, 7 \%$ \\
\hline Beneficios Previdenciários - Rural & 56.089 & $7,9 \%$ & 111.310 & $9,0 \%$ & 124.705 & $9,7 \%$ \\
\hline Pessoal e Encargos Sociais (Inativos e pensionistas) & 74.046 & $10,5 \%$ & 110.777 & $8,9 \%$ & 122.088 & $9,5 \%$, \\
\hline Beneficios de Prestaçăo Continuada da LOAS/RMV & 22.502 & $3,2 \% i$ & 48.990 & $3,9 \%$ i & 53.635 & $4,2 \% 1$ \\
\hline Pessoal e Encargos Sociais (Ativos) & 94.359 & $\overline{13}, \overline{4} \%$ & $-1 \overline{47.09 \overline{4}}$ & $11,8 \%$ & 160.985 & $\overline{12}, \overline{5} \%$ \\
\hline Gasto da Saúde (exc.pessoal) & 51.745 & $7,3 \%$ & 99.804 & $8,0 \%$ & 103.834 & $8,0 \%$ \\
\hline Seguro Desemprego & 20.779 & $2,9 \%$ & 37.667 & $3,0 \%$ & 41.977 & $3,3 \%$ \\
\hline Gasto da Assistencia Social (exceto pessoal e BPC) (inclui Bolsa Familia) & 16.565 & $2.3 \%$ & 32.056 & $2,6 \%$ & 31.654 & $2.5 \%$ \\
\hline Gasto da Educaçăo (exc.pessoal) & 18.830 & $2,7 \%$ & 34.543 & $2,8 \%$ & 31.360 & $2,4 \%$ \\
\hline PAC & 22.082 & $3,1 \%$ & 42.043 & $3,4 \%$ & 26.776 & $2,1 \%$ \\
\hline Subsidios, Subvençð̄es e Proagro & 4.742 & $0,7 \%$ & 23.328 & $1,9 \%$ & 26.754 & $2,1 \%$ \\
\hline Abono & 9.029 & $1,3 \%$ & 18.347 & $1,5 \%$ & 16.930 & $1,3 \%$ \\
\hline Poder Legislativo, Judiciário e Ministério Público da Uniððo & 6.665 & $0,9 \%$ & 13.004 & $1,0 \%$ & 14.224 & $1,1 \%$ \\
\hline Compensaçăo ao RGPS pelas Desoneraçð̌es da Folha & - & $0,0 \%$ & 17.593 & $1,4 \%$ & 13.822 & $1,1 \%$ \\
\hline FUNDEB (Complem. União) & 5.353 & $0,8 \%$ & 13.675 & $1,1 \%$ & 13.037 & $1,0 \%$ \\
\hline Sentenças Judiciais e Precatórios & 2.095 & $0,3 \%$ & 10.163 & $0,8 \%$ & 11.182 & $0,9 \%$ \\
\hline Demais Despesas Obrigatórias & 24.535 & $3,5 \%$ & 36.171 & $2,9 \%$ & 17.694 & $1,4 \%$ \\
\hline Demais Despesas Discricionárias do Executivo & 78.202 & $11,1 \%$ & 49.246 & $4,0 \%$ & 44.146 & $3,4 \%$ \\
\hline Despesa total & 706.388 & $100,0 \%$ & 1.242 .373 & $100,0 \%$ & 1.289 .865 & $100,0 \%$ \\
\hline
\end{tabular}

Fonte: PLDO 2018 (BRASIL, 2018e, p. 7) $)^{15}$.

Se compararmos o custo efetivo do Fies em 2016, estimado pela STN à época em R\$ 30,28 bilhões, com a composição da despesa primária da União do mesmo ano (Tabela 9), constataremos que o orçamento do Fies nesse ano, quando comparado com o gasto em educação - R $\$ 31,36$ bilhões (Tabela 9 - linha em destaque), desconsiderados os custos com pessoal e encargos sociais, resulta numa proporção de 96,55\%. Em relação, ainda, à despesa com Assistência Social (exceto pessoal e Benefício de Prestação Continuada), de R\$ 31,65 bilhões, o Fies representou 95,67\%.

Cabe retomar o paralelo entre as despesas do Fies e da complementação da União ao Fundeb. Esta última, conforme o estudo de Mendes (2015), representava 64\% das despesas do Fies em 2014. Já em 2017, representou pouco mais de um terço, embora tenha beneficiado em torno de 15,5 milhões de alunos nos nove estados cobertos, ante os 2,7 milhões de beneficiários do Fies no mesmo ano. Embora o mesmo autor defenda uma reorientação dos gastos públicos para as séries iniciais - "[...] uma reorientação de gastos, privilegiando as etapas iniciais da educação, provavelmente repercutiriam mais positivamente sobre a distribuição de renda e produtividade da mão de obra em geral" (MENDES, 2015, p. 13), reiteramos que a comparação de despesas com os dois níveis precisa ser complexificada, tendo em conta os custos do ensino. De todo modo, a Tabela 9 mostra que ocorreu uma contração na complementação da União ao Fundeb, decorrente da queda dos recursos globais do Fundeb dos governos subnacionais e da decisão de manter a complementação no nível mínimo obrigatório (10\% dos recursos dos estados, DF e municípios).

\section{Fies - presente e futuro próximo, à guisa de conclusão}

Tantas análises, realizadas por múltiplos e distintos grupos e órgãos, culminaram na MP $n^{\circ}$ 785/2017 (BRASIL, 2017b), convertida em Lei $n^{\circ} 13.530$ do mesmo ano (BRASIL, 2017a), reformulando o Fies novamente, após mais de 300 emendas ao texto original. Atualmente o Fies opera em duas modalidades: Fies e P-Fies, conforme disposto pela Portaria MEC $\mathrm{n}^{\circ} 209$, de 7 de março de 2018 (BRASIL, 2018d), em que a primeira (Fies) está "[...] sob a

15 Despesas pagas. Para inativos e pensionistas, despesa empenhada (BRASIL, 2018c, p. 7). 
responsabilidade do agente operador do Fies poderá ser garantida pelo Fundo Garantidor do Fies - FG-Fies, e pode ser acessada por estudantes que tenham perfil de renda bruta familiar per capita de até 3 (três) salários mínimos", e, a segunda (P-Fies), "é concretizada por meio de fontes de financiamento distintas do Fies", e são operadas "sob a responsabilidade de agentes financeiros operadores de crédito", e que "[...] não poderá ser garantida pelo FG-Fies e pode ser acessada por estudantes que tenham perfil de renda bruta familiar per capita de 3 (três) salários mínimos até 5 (cinco) salários mínimos".

$\mathrm{Na}$ esteira das mudanças e do atual contexto político nacional, cabe perguntar: e o Fies após 2019? A assunção de novos mandatos no Executivo e Legislativo federais aponta para a tendência de fortalecer o setor privado no atendimento de serviços públicos. Talvez estejamos diante de uma elite que eternizou "[...] seu acesso aos cofres públicos como coisa sua, assalto que sua imprensa comprada comemora como vitória da 'austeridade' contra o 'populismo'", como cogita Souza (2019, p. 251)? Em meio a um claudicante período de adaptações no MEC, defrontamo-nos com as dificuldades para uma a análise concreta do ano de 2020. Em linhas muito amplas, o Fies encerrou 2019 com aproximadamente $R \$ 8,9$ bilhões executados (FNDE, 2019b), entre os 1.786.271 contratos mantidos em 2018 , e 2.554.498 ativos, totalizando uma dívida ativa acumulada de $\mathrm{R} \$ 98,9$ bilhões, até 31 de dezembro de 2018 (FNDE, 2019a). Seu custo consolidado, até 31 de dezembro de 2022, confirmadas as expectativas expostas na Tabela 8 , pode chegar a $R \$ 185,08$ bilhões.

Outras mudanças relacionadas ao Fies no primeiro semestre de 2018, como a Lei $n^{\circ}$ 13.682 (FNDE, 2018i) (BRASIL, 2018a), terminariam por concretizar aquilo que muitos já profetizavam desde a sua criação: tornar-se uma releitura do Creduc, que, após décadas de inadimplência, terminou por "torrar" muitos contratos ${ }^{16}$. Não obstante, a despeito do prejuízo que o Fies já demonstra, o FNDE lançou mão de novo artifício de amortização de dívidas contraídas junto ao Programa, através da Portaria $n^{\circ}$ 154/2019, (FNDE, 2019c), dispondo sobre nova oportunidade de renegociação de passivos junto ao FGEDUC ${ }^{17}$.

Desde 1999 o Fies passou por importantes reformulações, e muitas vezes tem ocupado o centro da agenda pública e governamental, seja pelo viés de garantia da expansão do acesso à educação superior, seja pelo caráter neoliberal que lhe é subjacente. Entre os achados do presente estudo, concluímos que o Fies representa uma opção de acesso ao ensino superior, mas também uma fonte de sustentabilidade das instituições de educação superior privadas, as quais nem sempre efetivam o comprometimento social esperado.

De todo modo, o Fies tem longa trajetória e suas configurações demarcam novas deliberações que venham a ser formuladas. De outra parte, possíveis mudanças também estarão delimitadas pela atual conjuntura político-econômica do país, na qual é provável que não sejam revertidos os persistentes benefícios do financiamento público da oferta privada de educação superior. Ainda, no que tange ao cumprimento da Meta 12.6 do PNE 2014-2024, é

16 No caso da sanção supramencionada, foi autorizado aos agentes financeiros do Programa: [...] pactuar condições especiais de amortização ou alongamento excepcional de prazos para os estudantes inadimplentes com o Fies, por meio de estímulos à liquidação, ao reparcelamento e ao reescalonamento das dívidas do Fies, admitida a concessão de descontos incidentes sobre os encargos contratuais e o saldo devedor da dívida, conforme estabelecido em regulamento editado pelo Ministério da Educação, nos termos do que for aprovado pelo CG-Fies..

17 Segundo o então Presidente do FNDE, Carlos Alberto Decotelli da Silva, o Fies teria mais de 500 mil contratos em situação de inadimplemento, cujo atraso gira em torno de R\$10,9 bilhões (FNDE, 2019c). 
possível afirmar, concordando com Alves e Carvalho (2020, p. 9), que o Fies, até 2014, expandiu o financiamento estudantil e ampliou os benefícios destinados à concessão de financiamentos a estudantes de cursos superiores (Meta 12.20). Contudo, desde 2015, o programa vê-se eclipsado em diversas mudanças, e, desde 2019, atende um número cada vez menor de interessados em acessar a educação terciária utilizando tal recurso.

\section{Referências}

ALVES, Danubia Fernandes; CARVALHO, Cristina Helena Almeida De. O impacto da expansão do Fies entre 2010 e 2017 no cumprimento estratégico 12.6 do PNE (2014-2024). FINEDUCA - Revista de Financiamento da Educação, v. 10, n. 6, p. 1-13, 2020. Disponível em: https://seer.ufrgs.br/fineduca/article/view/90497. Acesso em: 8 jul. 2020.

BARROS, Helena Heller D. De. Financiamento estudantil. Brasília: Câmara dos Deputados, 2003. Disponível em: http://www2.camara.leg.br/a-camara/documentos-e-pesquisa/estudose-notas-tecnicas/arquivos-pdf/pdf/313903.pdf. Acesso em: 23 jul. 2020.

BB. Banco do Brasil. Fies: Aportes no FGEDUC-FG-FIES - $2011 \rightarrow$ Demonstrações contábeis 2011. Brasília: Banco do Brasil, 2011. Disponível em: https://www.bb.com.br/docs/pub/gov/ dwn/FGEDUCDemContFin2011.pdf. Acesso em: 2 mar. 2020.

BB. Banco do Brasil. Fies: Aportes no FGEDUC-FG-FIES - $2012 \rightarrow$ Demonstrações contábeis 2012. Brasília: Banco do Brasil, 2012. Disponível em: https://www.bb.com.br/docs/pub/gov /dwn/FGEDUCDemContFin2012.pdf. Acesso em: 2 mar. 2020.

BB. Banco do Brasil. Fies: Aportes no FGEDUC-FG-FIES - $2013 \rightarrow$ Demonstrações contábeis 2013. Brasília: Banco do Brasil, 2013. Disponível em: https://www.bb.com.br/docs/pub/gov /dwn/FGEDUCDemContFin2013.pdf. Acesso em: 2 mar. 2020.

BB. Banco do Brasil. Fies: Aportes no FGEDUC-FG-Fies - $2014 \rightarrow$ Demonstrações contábeis 2014. Brasília: Banco do Brasil, 2014. Disponível em: https://www.bb.com.br/docs/pub/gov/ dwn/FGEDUCDemContFin2014.pdf. Acesso em: 2 mar. 2020.

BB. Banco do Brasil. Fies: Aportes no FGEDUC-FGFies $\rightarrow$ Relatório de administração do FGEDUC - Exercícios 2011, 2012, 2013, 2014. Brasília: Banco do Brasil, 2015. Disponível em: https://www.bb.com.br/docs/pub/gov/dwn/FGEDUCRA20112014.pdf. Acesso em: 2 mar. 2020.

BB. Banco do Brasil. Fies: Aportes no FGEDUC-FG-Fies $\rightarrow$ Relatório de administração do FGEDUC - Exercícios 2015 e 2016. Brasília: Banco do Brasil, 2018a. Disponível em: https://www.bb.com.br/docs/pub/gov/dwn/FGEDUCRA2016.pdf. Acesso em: 2 mar. 2020.

BB. Banco do Brasil. Fies: Aportes no FGEDUC-FG-Fies $2017 \rightarrow$ Relatório da administração 2017. Brasília: Banco do Brasil, 2018b. Disponível em: http://www.in.gov.br/materia/lasset_publisher/Kujrw0TZC2Mb/content/id/6255999/do1-2018-03-13-relatorio-daadministracao-6255995. Acesso em: 2 mar. 2020.

BRASIL. Exposição de Motivos n 393 , de 18 de agosto de 1975. Institui o Programa de Crédito Educativo. Câmara dos Deputados, Brasília, 1975. Disponível em: https://www.camara.leg.br/proposicoesWeb/prop_mostrarintegra;jsessionid=E2A4D862E534 
Reformulações e Implementação do Fies (1999-2020)

9D9F2F69546A352B0D11. proposicoesWeb1?codteor=1180111\&amp;filename=Avulso+PL+1914/1979. Acesso em: 20 jul. 2020.

BRASIL. Lei no 8.436, de 25 de junho de 1992. Institucionaliza o Programa de Crédito Educativo para estudantes carentes. Diário Oficial da União, Brasília, 1992. Disponível em: https://www2.camara.leg.br/legin/fed/lei/1992/lei-8436-25-junho-1992-357678-

publicacaooriginal-1-pl.html. Acesso em: 13 jul. 2020.

BRASIL. Medida Provisória no 1.827, de 27 de maio de 1999. Dispõe sobre o Fundo de Financiamento ao Estudante do Ensino Superior e dá outras providências. Diário Oficial da União, Brasília, 1999a. Disponível em: https://www2.camara.leg.br/legin/fed/medpr o/1999/medidaprovisoria-1827-27-maio-1999-378036-publicacaooriginal-1-pe.html. Acesso em: 13 jul. 2020.

BRASIL. Medida Provisória n 1.865-2, de 29 de Junho de 1999. Dispõe sobre o Fundo de Financiamento ao Estudante do Ensino Superior e dá outras providências. Diário Oficial da União, Brasília, 1999b. Disponível em: https://www2.camara.leg.br/legin/fed/medp ro/1999/medidaprovisoria-1865-2-29-junho-1999-375146-publicacaooriginal-1-pe.html.

Acesso em: 13 jul. 2020.

BRASIL. Medida Provisória n 1.972-8, de 10 de dezembro de 1999. Dispõe sobre o Fundo de Financiamento ao Estudante do Ensino Superior e dá outras providências. Diário Oficial da União, Brasília, 1999c. Disponível em: https://www.planalto.gov.br/ccivil_03/ mpv/antigas/1972-8.htm. Acesso em: 13 jul. 2020.

BRASIL. Banco Central. Resolução no 2.647, de 22 de setembro de 1999. Regulamenta dispositivos da Medida Provisória no 1.865-4, de 1999, que trata do Fundo de Financiamento ao Estudante do Ensino Superior - FIES. Diário Oficial da União, Brasília, 1999d. Disponível em: https://www.legisweb.com.br/legislacao/?id=96543. Acesso em: 20 jul. 2020.

BRASIL. Ministério da Educação. Portaria $n^{\circ}$ 860, de 27 de maio de 1999. Estabelece as diretrizes para o Fundo de Financiamento ao Estudante do Ensino Superior. Brasília, 1999e. Disponível em: http://portal.mec.gov.br/sesu/arquivos/pdf/Portaria n860.pdf. Acesso em: 20 jul. 2020.

BRASIL. Ministério da Educação. Portaria n 1.386, de 15 de setembro de 1999. Dispõe sobre procedimentos para inscrição dos candidatos ao Fundo de Financiamento ao Estudante do Ensino Superior - FIES e dá outras providências. Brasília, 1999f. Disponível em: https://www.normasbrasil.com.br/norma/portaria-1386-1999_181368.html. Acesso em: 20 jul. 2020.

BRASIL. Ministério da Fazenda. Fies: Relatório de gestão do exercício de 1999. Brasília: SIAFI, 1999g.

BRASIL. Medida Provisória $n^{\circ}$ 2.094-22, de 27 de dezembro de 2000. Dispõe sobre o Fundo de Financiamento ao Estudante do Ensino Superior e dá outras providências. Diário Oficial da União, Brasília, 2000. Disponível em: http://www.planalto.gov.br/ccivil_03/mpv/ Antigas/2094-22.htm. Acesso em: 13 jul. 2020. 
BRASIL. Lei no 10.260, de 12 de julho de 2001. Diário Oficial da União, Brasília, 2001. Disponível em: https://www2.camara.leg.br/legin/fed/lei/2001/lei-10260-12-julho-2001329619-publicacaooriginal-1-pl.html. Acesso em: 13 jul. 2020.

BRASIL. Medida Provisória $\mathrm{n}^{\circ}$ 213, de 10 de setembro de 2004. Institui o Programa Universidade para Todos - PROUNI, regula a atuação de entidades beneficentes de assistência social no ensino superior, e dá outras providências. Diário Oficial da União, Brasília, 2004. Disponível em: http://www.planalto.gov.br/ccivil_03/Ato20042006/2004/Mpv/213.htm. Acesso em: 13 jul. 2020.

BRASIL. Lei n 11.096, de 13 de janeiro de 2005. Institui o Programa Universidade para Todos - PROUNI, regula a atuação de entidades beneficentes de assistência social no ensino superior; altera a Lei no 10.891, de 9 de julho de 2004, e dá outras providências. Diário Oficial da União, Brasília, 2005. Disponível em: http://www.planalto.gov.br/ccivil_03/_Ato20042006/2005/Lei/L11096.htm. Acesso em: 13 jul. 2020.

BRASIL. Banco Central. Resolução $n^{\circ} 3.415$, de 13 de outubro de 2006 . Regulamenta o inciso II do art. $5^{\circ}$ da Lei $n^{\circ} 10.260$, de 12 de julho de 2001, que trata do Fundo de Financiamento ao Estudante do Ensino Superior - FIES. Diário Oficial da União, Brasília, 2006. Disponível em: http://www.bcb.gov.br/pre/normativos/res/2006/pdf/res_3415_v1_O.pdf. Acesso em: 20 jul. 2020.

BRASIL. Ministério da Educação. Fies: Relatório de gestão do exercício de 2008. Brasília: Ministério da Educação, 2008. Disponível em: http://portal.mec.gov.br/index.php? option=com_docman\&view=download\&alias=2708-relatorioagregadocontas-fies-pce2008\&category_slug=janeiro-2010-pdf\&ltemid=30192. Acesso em: 14 jul. 2020.

BRASIL. Lei no 12.087, de 11 de novembro de 2009. Dispõe sobre a prestação de auxílio financeiro pela União aos Estados, ao Distrito Federal e aos Municípios, no exercício de 2009, com o objetivo de fomentar as exportações do País, e sobre a participação da União em fundos garantidores de risco de crédito para micro, pequenas e médias empresas e para produtores rurais e suas cooperativas; e altera as Leis nos 11.491, de 20 de junho de 2007, 8.036, de 11 de maio de 1990, e 8.001, de 13 de março de 1990. Diário Oficial da União, Brasília, 2009a. Disponível em: http://www.planalto.gov.br/ccivil_03/_Ato20072010/2009/Lei/L12087.htm. Acesso em: 13 jul. 2020.

BRASIL. Ministério da Educação. Fies: Relatório de gestão do exercício de 2009. Brasília: Ministério da Educação, 2009b. Disponível em: http://portal.mec.gov.br/index.php ?option=com_docman\&view=download\&alias=17557-fies-relatorio-de-gestao2009\&category_slug=maio-2015-pdf\&Itemid=30192. Acesso em: 14 jul. 2020.

BRASIL. Lei $n^{\circ} 12.202$, de 14 de janeiro de 2010. Altera a Lei $n^{\circ} 10.260$, de 12 de julho de 2001, que dispõe sobre o Fundo de Financiamento ao Estudante do Ensino Superior - FIES (permite abatimento de saldo devedor do FIES aos profissionais do magistério público e médicos dos programas de saúde da família; utilização de débitos com o INSS como crédito do FIES pelas instituições de ensino; e dá outras providências). Diário Oficial da União, Brasília, 2010a. Disponível em: https://www2.camara.leg.br/legin/fed/lei/2010/lei-12202-14janeiro-2010-600572-publicacaooriginal-122481-pl.html. Acesso em: 13 jul. 2020. 
Reformulações e Implementação do Fies (1999-2020)

BRASIL. Medida Provisória n 501 , de 8 de setembro de 2010. Dispõe sobre a prestação de auxílio financeiro pela União aos Estados, ao Distrito Federal e aos Municípios, no exercício de 2010, com o objetivo de fomentar as exportações do País; altera as Leis no 12.087, de 11 de novembro de 2009, e $n^{\circ} 10.260$, de 12 de julho de 2001; modifica condições para a concessão da subvenção em operações de financiamento de que trata $\mathrm{o}$ art. $1^{\circ}$ da Lei $\mathrm{n}^{\circ}$ 12.096, de 24 de novembro de 2009, que autoriza a concessão de subvenção econômica ao Banco Nacional de Desenvolvimento Econômico e Social - BNDES, em operações de financiamento destinadas à aquisição e produção de bens de capital e à inovação tecnológica; e dá outras providências. Diário Oficial da União, Brasília, 2010b. Disponível em: http://www.planalto.gov.br/ccivil_03/_Ato2007-2010/2010/Mpv/501.htm. Acesso em: 13 jul. 2020.

BRASIL. Ministério da Educação. Fies: Relatório de gestão do exercício de 2010. Brasília: Ministério da Educação, 2010c. Disponível em: http://portal.mec.gov.br/index.php? option=com_docman\&view=download\&alias=17558-fies-relatorio-de-gestao2010\&category_slug=maio-2015-pdf\&Itemid=30192. Acesso em: 14 jul. 2020.

BRASIL. Ministério da Fazenda. Fies: Aportes no FGEDUC-FGFies - $2010 \rightarrow$ Portaria n $^{\circ}$ 573, de 14 de dezembro de 2010. Fica autorizada a transferência para o Fundo de Garantia de Operações de Crédito Educativo - FGEDUC, de que trata a Lei no 12.087 , de 11 de novembro de 2009. Brasília, 2010d. Disponível em: https://www.jusbrasil.com.br/diarios/23891845/pg25-secao-1-diario-oficial-da-uniao-dou-de-16-12-2010. Acesso em: 22 jul. 2020.

BRASIL. Lei n 12.385, de 3 de março de 2011. Dispõe sobre a prestação de auxílio financeiro pela União aos Estados, ao Distrito Federal e aos Municípios, no exercício de 2010, com o objetivo de fomentar as exportações do País; altera as Leis n's 12.087 , de 11 de novembro de 2009, 10.260, de 12 de julho de 2001, 8.685, de 20 de julho de 1993, 3.890-A, de 25 de abril de 1961, 10.848, de 15 de março de 2004, 12.111, de 9 de dezembro de 2009, e 12.249, de 11 de junho de 2010; modifica condições para a concessão da subvenção em operações de financiamento de que trata o art. $1^{\circ}$ da Lei $n^{\circ} 12.096$, de 24 de novembro de 2009; revoga dispositivo da Lei $n^{\circ} 12.096$, de 24 de novembro de 2009; e dá outras providências. Diário Oficial da União, Brasília, 2011a. Disponível em: http://www.planalto.gov.br/ccivil_03 I_ato2011-2014/2011/lei/l12385.htm. Acesso em: 13 jul. 2020.

BRASIL. Ministério da Educação. Fundo atinge a marca de $\mathbf{5 0 5 , 7}$ mil contratos firmados apenas este ano. Brasília, 2011b. Disponível em: http://portal.mec.gov.br/component/t ags/tag/35597. Acesso em: 20 jul. 2020.

BRASIL. Ministério da Educação. Fies: Relatório de gestão do exercício de 2011. Brasília: Ministério da Educação, 2011c. Disponível em: http://portal.mec.gov.br/index .php?option=com_docman\&view=download\&alias=17559-fies-relatorio-de-gestao2011\&category_slug=maio-2015-pdf\&Itemid=30192. Acesso em: 14 jul. 2020.

BRASIL. Ministério da Educação. Fies: Relatório de gestão do exercício de 2012. Brasília: Ministério da Educação, 2012. Disponível em: http://portal.mec.gov.br/index .php?option=com_docman\&view=download\&alias=14253-relatorio-gestao-da-fies-exercicio2012-pdf\&category_slug=setembro-2013-pdf\&Itemid=30192. Acesso em: 14 jul. 2020. 
BRASIL. Ministério da Educação. Fies: Relatório de gestão do exercício de 2013. Brasília: Ministério da Educação, 2013. Disponível em: http://portal.mec.gov.br/index. php?option=com_docman\&view=download\&alias=15998-relatorio-gestao-exercicio-2013fies-pdf\&category_slug=julho-2014-pdf\&ltemid=30192. Acesso em: 14 jul. 2020.

BRASIL. Ministério da Educação. Portaria Normativa n 3, de 13 de janeiro de 2014. Altera dispositivos das Portarias Normativas MEC $n^{\circ} 1$, de 22 de janeiro de 2010, n० 10, de 30 de abril de 2010, e $\mathrm{n}^{\circ} 15$, de 8 de julho de 2011, que dispõem sobre o Fundo de Financiamento Estudantil - Fies. Diário Oficial da União, Brasília, 2014a. Disponível em: http://portal.mec.gov.br/index.php?option=com_docman\&view=download\&alias=15004portaria-norm-03-2014\&category_slug=janeiro-2014-pdf\&ltemid=30192. Acesso em: 20 jul. 2020.

BRASIL. Ministério da Educação. Fies: Relatório de gestão do exercício de 2014. Brasília: Ministério da Educação, 2014b. Disponível em: http://portal.mec.gov.br/index.php? option=com_docman\&view=download\&alias=17528-fies-relatorio-gestao-pcoa-exercicio2014-tcu\&category_slug=maio-2015-pdf\&ltemid=30192. Acesso em: 14 jul. 2020.

BRASIL. Ministério da Fazenda. Fies: Aportes no FGEDUC-FGFies - $2014 \rightarrow$ Portaria n 195, de 15 de abril de 2014. Autorizar a transferência para o Fundo de Garantia de Operações de Crédito Educativo - FGEDUC de até 1.048.913.630 ações ordinárias do Banco da Amazônia S.A., de até 30.219.768 ações ordinárias do Banco do Nordeste do Brasil S.A., e de até 37.572.730 ações ordinárias das Centrais Elétricas Brasileiras S.A. - ELETROBRAS, excedentes ao necessário à manutenção do controle na União. Brasília, 2014c. Disponível em: https://e-dou.com.br/2014/04/diario-oficial-da-uniao-secao-1-17-04-2014/. Acesso em: 22 jul. 2020.

BRASIL. Banco Central. Resolução no 4.432, de 23 de julho de 2015. Fixa a taxa efetiva de juros do Fundo de Financiamento ao Estudante do Ensino Superior (FIES). Diário Oficial da União, Brasília, 2015a. Disponível em: https://www.bcb.gov.br/pre/normativos /busca/downloadNormativo.asp?arquivo=/Lists/Normativos/Attachments/48510/Res_4432_v 1_O.pdf. Acesso em: 20 jul. 2020.

BRASIL. Ministério da Educação. Fies: Relatório de gestão do exercício de 2015. Brasília: Ministério da Educação, 2015b. Disponível em: http://portal.mec.gov.br/index.php? option=com_docman\&view=download\&alias=49921-rg-fies-2015-

pdf\&category_slug=outubro-2016-pdf\&Itemid=30192. Acesso em: 14 jul. 2020.

BRASIL. Ministério da Fazenda. Financiamento estudantil: indicadores e insights sobre a focalização do programa. Boletim de Avaliação de Políticas Públicas, v. 1, n. 2, p. 1-14, 2015c. Disponível em: https://sisweb.tesouro.gov.br/apex/f?p=2501:9::::9:P9_ ID_PUBLICACAO:30717. Acesso em: 20 jul. 2020.

BRASIL. Ministério da Fazenda. Financiamento estudantil - insights sobre as condições de financiamento e o risco fiscal. Boletim de Avaliação de Políticas Públicas, v. 1, n. 3, p. 110, 2015d. Disponível em: https://sisweb.tesouro.gov.br/apex/f?p=2501:9::::9:P9_ ID_PUBLICACAO:28268. Acesso em: 20 jul. 2020.

BRASIL. Ministério da Fazenda. Fies: Aportes no FGEDUC-FGFies $2015 \rightarrow$ Portaria n 644, de 17 de agosto de 2015. Foi autorizada a integralização pela União das cotas do FGEDUC, 
Reformulações e Implementação do Fies (1999-2020)

mediante a transferência de 49.161.763 ações ordinárias de emissão da Companhia. Brasília, 2015e. Disponível em: http://www.bbseguridaderi.com.br/pt/documentos/910-ProspectoDefinitivo.pdf. Acesso em: 22 jul. 2020.

BRASIL. Ministério da Educação. Fies: Relatório de gestão do exercício de 2016. Brasília: Ministério da Educação, 2016a. Disponível em: http://portal.mec.gov.br/index .php?option=com_docman\&view=download\&alias $=66631$-relatorio-gestao-fies-exercicio2016-pdf\&category_slug=junho-2017-pdf\&ltemid=30192. Acesso em: 14 jul. 2020.

BRASIL. Ministério da Fazenda. Fies: Aportes no FGEDUC-FG-FIES $2016 \rightarrow$ Portaria n $^{\circ}$ 502, de 28 de dezembro de 2016. Fica autorizada a integralização de cotas, em moeda corrente, pela União, no Fundo de Garantia e Operações de Crédito Educativo - FGEDUC, de que trata a Lei $n^{\circ} 12.087$, de 11 de novembro de 2009 , no montante de $\mathrm{R} \$ 563.840 .861,57$ (quinhentos e sessenta e três milhões, oitocentos e quarenta mil, oitocentos e sessenta e um de reais e cinquenta e sete centavos). Brasília, 2016b. Disponível em: http://pesquisa.in.gov.br/imprensa/servlet/INPDFViewer?jornal=1000\&pagina=1\&data=28/12/ 2016\&captchafield=firstAccess. Acesso em: 22 jul. 2020.

BRASIL. Lei $n^{\circ} 13.530$, de 7 de dezembro de 2017. Altera a Lei $n^{\circ} 10.260$, de 12 de julho de 2001, a Lei Complementar $n^{\circ} 129$, de 8 de janeiro de 2009, a Medida Provisória $n^{\circ}$ 2.156-5, de 24 de agosto de 2001, a Medida Provisória n².157-5, de 24 de agosto de 2001, a Lei no 7.827, de 27 de setembro de 1989, a Lei $n^{\circ}$ 9.394, de 20 de dezembro de 1996 (Lei de Diretrizes e Bases da Educação Nacional), a Lei no 8.958, de 20 de dezembro de 1994, a Lei $\mathrm{n}^{\circ}$ 9.766, de 18 de dezembro de 1998, a Lei $\mathrm{n}^{\circ} 8.745$, de 9 de dezembro de 1993, a Lei $\mathrm{n}^{\circ}$ 12.101, de 27 de novembro de 2009, a Lei no 12.688, de 18 de julho de 2012, e a Lei $n^{\circ} 12.871$, de 22 de outubro de 2013; e dá outras providências. Diário Oficial da União, Brasília, 2017a. Disponível em: http://www.planalto.gov.br/ccivil_03/_ato2015-2018/2017/lei//13530.htm. Acesso em: 13 jul. 2020.

BRASIL. Medida Provisória $\mathrm{n}^{\circ}$ 785, de 6 de julho de 2017. Altera a Lei $\mathrm{n}^{\circ}$ 10.260, de 12 de julho de 2001, a Lei Complementar $n^{\circ} 129$, de 8 de janeiro de 2009, a Medida Provisória ${ }^{\circ}$ 2.156-5, de 24 de agosto de 2001, a Medida Provisória n².157-5, de 24 de agosto de 2001, a Lei $n^{\circ} 7.827$, de 27 de setembro de 1989, a Lei no 9.394, de 20 de dezembro de 1996, a Lei $n^{\circ}$ 8.958, de 20 de dezembro de 1994, e dá outras providências. Diário Oficial da União, Brasília, 2017b. Disponível em: http://www.planalto.gov.br/ccivil_03/_Ato20152018/2017/Mpv/mpv785.htm. Acesso em: 13 jul. 2020.

BRASIL. Ministério da Educação. Fies: Relatório de gestão do exercício de 2017. Brasília: Ministério da Educação, 2017c. Disponível em: http://portal.mec.gov.br/index.php?option= com_docman\&view=download\&alias=98081-rg-fies-2017\&category_slug=outubro-2018-pdf1\&Itemid=30192. Acesso em: 14 jul. 2020.

BRASIL. Ministério da Fazenda. Diagnóstico FIES. Brasília: Ministério da Fazenda, 2017d. Disponível em: http://portal.mec.gov.br/index.php?option=com_docman\&view= download\&alias=66921-diagnosticofies-junho2017-pdf\&category_slug=julho-2017pdf\&Itemid=30192. Acesso em: 10 jul. 2018.

BRASIL. Lei $\mathrm{n}^{\circ} 13.682$, de 19 de junho de 2018. Altera as Leis $\mathrm{n} \times 10.177$, de 12 de janeiro de 2001, 7.827, de 27 de setembro de 1989, 8.167, de 16 de janeiro de 1991, e 10.260, de 12 de 
Reformulações e Implementação do Fies (1999-2020)

julho de 2001, as Medidas Provisórias n 2.156-5, de 24 de agosto de 2001, e 2.157-5, de 24 de agosto de 2001, e a Lei Complementar no 129, de 8 de janeiro de 2009, para modificar a metodologia de cálculo dos encargos financeiros incidentes sobre as operações de crédito não rural com recursos de Fundos Constitucionais de Financiamento e a sistemática de remuneração dos respectivos bancos administradores; e revoga dispositivos da Lei $n^{\circ}$ 9.126, de 10 de novembro de 1995, e da Medida Provisória n².199-14, de 24 de agosto de 2001. Diário Oficial da União, Brasília, 2018a. Disponível em: https://www.planalto.gov.br/ccivil_ 03/_ato2015-2018/2018/lei//13682.htm. Acesso em: 13 jul. 2020.

BRASIL. Decreto $n^{\circ}$ 9.292, de 23 de fevereiro de 2018. Estabelece as características dos títulos da Dívida Pública Mobiliária Federal e dá outras providências. Diário Oficial da União, Brasília, 2018b. Disponível em: http://www.planalto.gov.br/ccivil_03/_Ato20152018/2018/Decreto/D9292.htm. Acesso em: 21 jul. 2020.

BRASIL. Ministério da Educação. Manual do Programa de Crédito Educativo. Brasília: Ministério da Educação, 2018c. Disponível em: http://portal.mec.gov.br/sesu/ arquivos/pdf/mcreduc.pdf. Acesso em: 20 jul. 2020.

BRASIL. Ministério da Educação. Portaria n 209, de 7 de março de 2018. Dispõe sobre o Fundo de Financiamento Estudantil - Fies, a partir do primeiro semestre de 2018. Brasília, 2018d. Disponível em: http://fies.mec.gov.br/arquivos/portaria_209_07032018.pdf. Acesso em: 13 jul. 2020.

BRASIL. Ministério do Planejamento Orçamento e Gestão. Projeto de Lei de Diretrizes Orçamentárias - PLDO 2018. Brasília: Ministério do Planejamento, Orçamento e Gestão, 2018e. Disponível em: https://www.gov.br/economia/pt-br/centrais-deconteudo/apresentacoes/planejamento/2017/apresentacao-

pldo2018.pdf/@@download/file/apresentacao-pldo2018.pdf. Acesso em: 21 jul. 2020.

BRASIL. SIGA Brasil - Painel especialista do Senado. Brasília: Senado Federal, 2020a. Disponível em: http://www9.senado.leg.br/QvAJAXZfc/opendoc.htm?document= Senado\%2FSigaBrasilPainelEspecialista.qvw\&host=QVS\%40www9\&anonymous=true\&sele ct=LB137,2019. Acesso em: 21 jul. 2020.

BRASIL. Controladoria Geral da União. Fies: Repasse ao FGEDUC-FG-Fies CCG - 2018 e $2019 \rightarrow$ Portal da transparência. 2020b. Disponível em: http://www. portaltransparencia.gov.br/despesas/favorecido?faseDespesa=3\&favorecido=471 20188\&ordenarPor=valor\&direcao=desc. Acesso em: 3 mar. 2020.

BRASIL. Controladoria Geral da União. Fies: Aportes no FGEDUC-FG-Fies 2015, 2016, 2017 , 2018, $2019 \rightarrow$ Portal da transparência. 2020c. Disponível em: http://www.portaltransparencia.gov.br/despesas/programa-e-

acao/consulta?paginacaoSimples=true\&tamanhoPagina $=\&$ offset $=\&$ direcaoOrdenacao $=a s c \&$ $\mathrm{de}=01 \% 2 \mathrm{~F} 01 \% 2 \mathrm{~F} 2015 \&$ ate $=31 \% 2 \mathrm{~F} 12 \% 2 \mathrm{~F} 2015$ \&programa=0909\&acao=00M2\&colunasSel ecionadas=linkDetalhamento\%2CmesAno\%2CorgaoSup. Acesso em: 2 mar. 2020.

BRASIL. Controladoria Geral da União. Fies: Administração Fies - 2014 até $2020 \rightarrow$ Portal da transparência. 2020d.

Disponível

em: http://www.portaltransparencia.gov.br/despesas/programa-eacao ?paginacaoSimples $=$ true\&tamanhoPagina $=\&$ offse $t=\&$ direcaoOrdenacao $=$ asc $\& d e=01 \% 2$ 
Reformulações e Implementação do Fies (1999-2020)

F01\%2F2014\&ate $=31 \% 2 F 12 \% 2 F 2014 \&$ acao=20RZ\&colunasSelecionadas=linkDetalhament o\%2CmesAno\%2Cprograma\%2Cacao\%2CvalorDespesaE. Acesso em: 2 mar. 2020.

BRASIL. Ministério da Economia. Relatório de benefícios tributários, financeiros e creditícios no período de 2003 a 2018. Brasília: Ministério da Economia, 2020e. Disponível em: https://www.gov.br/economia/pt-br/acesso-a-informacao/participacao-social/conselhos-eorgaos-colegiados/cmap/publicacoes/subsidios-da-uniao/gastos-com-subsidios/osu/3oorcamento-subsidios-da-uniao-2019/@@download/file/3o-orcamento-subsidios-dauniao.pdf. Acesso em: 13 jul. 2020.

BRASIL. Ministério da Educação; CEF. Caixa Econômica Federal. Fies: Relatório de gestão do exercício de 2001. Brasília: Ministério da Educação, 2001. Disponível em: http://portal.mec.gov.br/index.php?option=com_docman\&view=download\&alias=17549-fiesrelatorio-de-gestao-2001\&category_slug=maio-2015-pdf\&ltemid=30192. Acesso em: 13 jul. 2020.

BRASIL. Ministério da Educação; CEF. Caixa Econômica Federal. Fies: Relatório de gestão do exercício de 2002. Brasília: Ministério da Educação, 2002. Disponível em: http://portal.mec.gov.br/index.php?option=com_docman\&view=download\&alias=17550-fiesrelatorio-de-gestao-2002\&category_slug=maio-2015-pdf\&Itemid=30192\%0A. Acesso em: 13 jul. 2020.

BURGARELLI, Rodrigo. Explosão e implosão do Fies: Como o ensino superior privado virou o centro dos gastos com educação do governo federal. In: MARINGONI, Gilberto (Ed.). 0 negócio da educação: aventuras na terra do capitalismo sem risco. São Paulo: Olho d'água, 2017. p. 37-54.

CEF. Caixa Econômica Federal. Fies: Relatório de gestão do exercício de 2000. Brasília: Ministério da Educação, 2000. Disponível em: http://portal.mec.gov.br/index.php? option=com_docman\&view=download\&alias=17548-fies-relatorio-de-gestao2000\&category_slug=maio-2015-pdf\&Itemid=30192. Acesso em: 13 jul. 2020.

CEF. Caixa Econômica Federal. Fies: Relatório de gestão do exercício de 2003. Brasília: Ministério da Educação, 2003. Disponível em: http://portal.mec.gov.br/index.php?option =com_docman\&view=download\&alias=17551-fies-relatorio-de-gestao-

2003\&category_slug=maio-2015-pdf\&Itemid=30192. Acesso em: 13 jul. 2020.

CEF. Caixa Econômica Federal. Fies: Relatório de gestão do exercício de 2004. Brasília: Ministério da Educação, 2004. Disponível em: http://portal.mec.gov.br/index.php?option= com_docman\&view=download\&alias=18231-relatorio-gestao-fies-mec-2004pdf\&category_slug=abril-2010-pdf\&Itemid=30192. Acesso em: 13 jul. 2020.

CEF. Caixa Econômica Federal. Fies: Relatório de gestão do exercício de 2005. Brasília: Ministério da Educação, 2005. Disponível em: http://portal.mec.gov.br/index.php?option= com_docman\&view=download\&alias=18241-relatorio-gestao-fies-mec-2005pdf\&category_slug=abril-2010-pdf\&ltemid=30192\%0A. Acesso em: 14 jul. 2020.

CEF. Caixa Econômica Federal. Fies: Relatório de gestão do exercício de 2006. Brasília: Ministério da Educação, 2006. Disponível em: http://portal.mec.gov.br/index.php?option= 
Reformulações e Implementação do Fies (1999-2020)

com_docman\&view=download\&alias=18251-relatorio-gestao-fies-mec-2006-

pdf\&category_slug=abril-2010-pdf\&ltemid=30192. Acesso em: 14 jul. 2020.

CEF. Caixa Econômica Federal. Fies: Relatório de gestão do exercício de 2007. Brasília: Ministério da Educação, 2007. Disponível em: http://portal.mec.gov.br/index.php?option= com_docman\&view=document\&alias=18261-relatorio-gestao-fies-mec-2007-

pdf\&category_slug=abril-2010-pdf\&ltemid=30192. Acesso em: 14 jul. 2020.

CEF. Caixa Econômica Federal. Fundo Garantidor do Fundo de Financiamento Estudantil

- FG-Fies. 2020. Disponível em: https://fundosdegoverno.caixa.gov.br/sicfg/fundos/FGFies/detalhe/sobre/. Acesso em: 2 ago. 2020.

CRUZ, Sofia Fernandes Valdo. Ministro da Fazenda anuncia pacote de aumento de impostos. Folha de São Paulo, Economia. São Paulo, p. 1, 2015. Disponível em: https://www1.folha.uol.com.br/mercado/2015/01/1577395-ministro-da-fazenda-anuncia-altade-impostos.shtml. Acesso em: 11 jul. 2018.

FILHO, João Ribeiro dos Santos; CHAVES, Vera Lúcia Jacob. O Financiamento Estudantil (FIES) e as implicações na financeirização de grupos educacionais. In: CHAVES, Vera Lúcia Jacob; AMARAL, Nelson Cardoso (Ed.). Políticas de financiamento da educação superior num contexto de crise. Campinas: Mercado de Letras, 2017. p. 71-98.

FNDE. Fundo Nacional de Desenvolvimento da Educação. Fies: Recompra de CFT-E 2010/2. Brasília: FNDE, 2010a. Disponível em: ftp://ftp2.fnde.gov.br/dadosabertos/FIES/ RECOMPRA_SEMESTRE_2_2010.csv. Acesso em: 21 jul. 2020.

FNDE. Fundo Nacional de Desenvolvimento da Educação. Fies: Repasse de CFT-E - 2010. Brasília: FNDE, 2010b. Disponível em: https://www.fnde.gov.br/index.php/centrais-deconteudos/publicacoes/category/221-mantenedora_ies?download=12353:repasse_2010.

Acesso em: 24 fev. 2020.

FNDE. Fundo Nacional de Desenvolvimento da Educação. Microdados: Fies - 2011/1. Brasília: FNDE, 2011a. Disponível em: ftp://ftp2.fnde.gov.br/dadosabertos/FIES/ FINANCIAMENTO_CONCEDIDOS_SEMESTRE_1_2011.csv. Acesso em: 27 fev. 2020.

FNDE. Fundo Nacional de Desenvolvimento da Educação. Microdados: Fies - 2011/2. Brasília: FNDE, 2011b. Disponível em: ftp://ftp2.fnde.gov.br/dadosabertos/FIES/ FINANCIAMENTO_CONCEDIDOS_SEMESTRE_2_2011.csv. Acesso em: 27 fev. 2020.

FNDE. Fundo Nacional de Desenvolvimento da Educação. Fies: Recompra de CFT-E 2011/2. Brasília: FNDE, 2011c.

FNDE. Fundo Nacional de Desenvolvimento da Educação. Fies: Recompra de CFT-E 2011/1. Brasília: FNDE, 2011d. Disponível em: ftp://ftp2.fnde.gov.br/dadosabertos/FIES/ RECOMPRA_SEMESTRE_1_2011.csv. Acesso em: 21 jul. 2020.

FNDE. Fundo Nacional de Desenvolvimento da Educação. Fies: Repasse de CFT-E - 2011. Brasília: FNDE, 2011e. Disponível em: https://www.fnde.gov.br/index.php/centrais-deconteudos/publicacoes/category/221-mantenedora_ies?download=12354:repasse_2011.

Acesso em: 24 fev. 2020. 
Reformulações e Implementação do Fies (1999-2020)

FNDE. Fundo Nacional de Desenvolvimento da Educação. Microdados: Fies - 2012/1. Brasília: FNDE, 2012a. Disponível em: ftp://ftp2.fnde.gov.br/dadosabertos/FIES/ FINANCIAMENTO_CONCEDIDOS_SEMESTRE_1_2012.csv. Acesso em: 27 fev. 2020.

FNDE. Fundo Nacional de Desenvolvimento da Educação. Microdados: Fies - 2012/2. Brasília: FNDE, 2012b. Disponível em: ftp://ftp2.fnde.gov.br/dadosabertos/FIES/ FINANCIAMENTO_CONCEDIDOS_SEMESTRE_2_2012.csv. Acesso em: 27 fev. 2020.

FNDE. Fundo Nacional de Desenvolvimento da Educação. Fies: Recompra de CFT-E 2012/1. Brasília: FNDE, 2012c. Disponível em: ftp://ftp2.fnde.gov.br/dadosabertos/FIES/ RECOMPRA_SEMESTRE_1_2012.csv. Acesso em: 21 jul. 2020.

FNDE. Fundo Nacional de Desenvolvimento da Educação. Fies: Recompra de CFT-E 2012/2. Brasília: FNDE, 2012d. Disponível em: ftp://ftp2.fnde.gov.br/dadosabertos/FIES/ RECOMPRA_SEMESTRE_2_2012.csv. Acesso em: 21 jul. 2020.

FNDE. Fundo Nacional de Desenvolvimento da Educação. Fies: Repasse de CFT-E - 2012. Brasília: FNDE, 2012e. Disponível em: https://www.fnde.gov.br/index.php/centrais-deconteudos/publicacoes/category/221-mantenedora_ies?download=12355:repasse_2012.

Acesso em: 24 fev. 2020.

FNDE. Fundo Nacional de Desenvolvimento da Educação. Microdados: Fies - 2013/1. Brasília: FNDE, 2013a. Disponível em: ftp://ftp2.fnde.gov.br/dadosabertos/FIES/ FINANCIAMENTO_CONCEDIDOS_SEMESTRE_1_2013.csv. Acesso em: 27 fev. 2020.

FNDE. Fundo Nacional de Desenvolvimento da Educação. Microdados: Fies - 2013/2. Brasília: FNDE, 2013b. Disponível em: ftp://ftp2.fnde.gov.br/dadosabertos/FIES/ FINANCIAMENTO_CONCEDIDOS_SEMESTRE_2_2013.csv. Acesso em: 27 fev. 2020.

FNDE. Fundo Nacional de Desenvolvimento da Educação. Fies: Recompra de CFT-E 2013/1. Brasília: FNDE, 2013c. Disponível em: ftp://ftp2.fnde.gov.br/dadosabertos/FIES/ RECOMPRA_SEMESTRE_1_2013.csv. Acesso em: 21 jul. 2020.

FNDE. Fundo Nacional de Desenvolvimento da Educação. Fies: Recompra de CFT-E 2013/2. Brasília: FNDE, 2013d. Disponível em: ftp://ftp2.fnde.gov.br/dadosabertos/FIES/ RECOMPRA_SEMESTRE_2_2013.csv. Acesso em: 21 jul. 2020.

FNDE. Fundo Nacional de Desenvolvimento da Educação. Fies: Repasse de CFT-E - 2013. Brasília: FNDE, 2013e. Disponível em: https://www.fnde.gov.br/index.php/centrais-deconteudos/publicacoes/category/221-mantenedora_ies?download=12356:repasse_2013.

Acesso em: 24 fev. 2020.

FNDE. Fundo Nacional de Desenvolvimento da Educação. Microdados: Fies - 2014/1. Brasília: FNDE, 2014a. Disponível em: ftp://ftp2.fnde.gov.br/dadosabertos/FIES/ FINANCIAMENTO_CONCEDIDOS_SEMESTRE_1_2014.csv. Acesso em: 27 fev. 2020.

FNDE. Fundo Nacional de Desenvolvimento da Educação. Microdados: Fies - 2014/2. Brasília: FNDE, 2014b. Disponível em: ftp://ftp2.fnde.gov.br/dadosabertos/FIES/ FINANCIAMENTO_CONCEDIDOS_SEMESTRE_2_2014.csv. Acesso em: 27 fev. 2020. 
Reformulações e Implementação do Fies (1999-2020)

FNDE. Fundo Nacional de Desenvolvimento da Educação. Fies: Recompra de CFT-E 2014/1. Brasília: FNDE, 2014c. Disponível em: ftp://ftp2.fnde.gov.br/dadosabertos/FIES/ RECOMPRA_SEMESTRE_1_2014.csv. Acesso em: 21 jul. 2020.

FNDE. Fundo Nacional de Desenvolvimento da Educação. Fies: Recompra de CFT-E 2014/2. Brasília: FNDE, 2014d. Disponível em: ftp://ftp2.fnde.gov.br/dadosabertos/FIES/ RECOMPRA_SEMESTRE_2_2014.csv. Acesso em: 21 jul. 2020.

FNDE. Fundo Nacional de Desenvolvimento da Educação. Fies: Repasse de CFT-E - 2014. Brasília: FNDE, 2014e. Disponível em: https://www.fnde.gov.br/index.php/centrais-deconteudos/publicacoes/category/221-mantenedora_ies?download=12357:repasse_2014.

Acesso em: 24 fev. 2020.

FNDE. Fundo Nacional de Desenvolvimento da Educação. Microdados: Fies - 2015/1. Brasília: FNDE, 2015a. Disponível em: ftp://ftp2.fnde.gov.br/dadosabertos/FIES/ FINANCIAMENTO_CONCEDIDOS_SEMESTRE_1_2015.csv. Acesso em: 27 fev. 2020.

FNDE. Fundo Nacional de Desenvolvimento da Educação. Microdados: Fies - 2015/2. Brasília: FNDE, 2015b. Disponível em: ftp://ftp2.fnde.gov.br/dadosabertos/FIES/ FINANCIAMENTO_CONCEDIDOS_SEMESTRE_2_2015.csv. Acesso em: 27 fev. 2020.

FNDE. Fundo Nacional de Desenvolvimento da Educação. Fies: Recompra de CFT-E 2015/2. Brasília: FNDE, 2015c. Disponível em: ftp://ftp2.fnde.gov.br/dadosabertos/FIES/ RECOMPRA_SEMESTRE_2_2015.csv. Acesso em: 21 jul. 2020.

FNDE. Fundo Nacional de Desenvolvimento da Educação. Fies: Recompra de CFT-E 2015/1. Brasília: FNDE, 2015d. Disponível em: ftp://ftp2.fnde.gov.br/dadosabertos/FIES/ RECOMPRA_SEMESTRE_1_2015.csv. Acesso em: 21 jul. 2020.

FNDE. Fundo Nacional de Desenvolvimento da Educação. Fies: Repasse de CFT-E - 2015. Brasília: FNDE, 2015e. Disponível em: https://www.fnde.gov.br/index.php/centrais-deconteudos/publicacoes/category/221-mantenedora_ies?download=12358:repasse_2015.

Acesso em: 24 fev. 2020.

FNDE. Fundo Nacional de Desenvolvimento da Educação. Microdados: Fies - 2016/1. Brasília: FNDE, 2016a. Disponível em: ftp://ftp2.fnde.gov.br/dadosabertos/FIES/ FINANCIAMENTO_CONCEDIDOS_SEMESTRE_1_2016.csv. Acesso em: 27 fev. 2020.

FNDE. Fundo Nacional de Desenvolvimento da Educação. Microdados: Fies - 2016/2. Brasília: FNDE, 2016b. Disponível em: ftp://ftp2.fnde.gov.br/dadosabertos/FIES/ FINANCIAMENTO_CONCEDIDOS_SEMESTRE_2_2016.csv. Acesso em: 27 fev. 2020.

FNDE. Fundo Nacional de Desenvolvimento da Educação. Fies: Recompra de CFT-E 2016/1. Brasília: FNDE, 2016c. Disponível em: ftp://ftp2.fnde.gov.br/dadosabertos/FIES/ RECOMPRA_SEMESTRE_1_2016.csv. Acesso em: 21 jul. 2020.

FNDE. Fundo Nacional de Desenvolvimento da Educação. Fies: Recompra de CFT-E 2016/2. Brasília: FNDE, 2016d. Disponível em: ftp://ftp2.fnde.gov.br/dadosabertos/FIES/ RECOMPRA_SEMESTRE_2_2016.csv. Acesso em: 21 jul. 2020.

FNDE. Fundo Nacional de Desenvolvimento da Educação. Fies: Repasse de CFT-E - 2016. Brasília: FNDE, 2016e. Disponível em: https://www.fnde.gov.br/index.php/centrais-de- 
Reformulações e Implementação do Fies (1999-2020)

conteudos/publicacoes/category/221-mantenedora_ies?download=12359:repasse_2016.

Acesso em: 24 fev. 2020.

FNDE. Fundo Nacional de Desenvolvimento da Educação. Microdados: Fies - 2017/1. Brasília: FNDE, 2017a. Disponível em: ftp://ftp2.fnde.gov.br/dadosabertos/FIES/ FINANCIAMENTO_CONCEDIDOS_SEMESTRE_1_2017.csv. Acesso em: 27 fev. 2020.

FNDE. Fundo Nacional de Desenvolvimento da Educação. Microdados: Fies - 2017/2. Brasília: FNDE, 2017b. Disponível em: ftp://ftp2.fnde.gov.br/dadosabertos/FIES/ FINANCIAMENTO_CONCEDIDOS_SEMESTRE_2_2017.csv. Acesso em: 27 fev. 2020.

FNDE. Fundo Nacional de Desenvolvimento da Educação. Fies: Recompra de CFT-E 2017/1. Brasília: FNDE, 2017c. Disponível em: ftp://ftp2.fnde.gov.br/dadosabertos/FIES/ RECOMPRA_SEMESTRE_1_2017.csv. Acesso em: 21 jul. 2020.

FNDE. Fundo Nacional de Desenvolvimento da Educação. Fies: Repasse de CFT-E - 2017. Brasília: FNDE, 2017d. Disponível em: https://www.fnde.gov.br/index.php/centrais-deconteudos/publicacoes/category/221-

mantenedora_ies?download=13086:repasses_fies_ano_2017. Acesso em: 24 fev. 2020.

FNDE. Fundo Nacional de Desenvolvimento da Educação. Histórico Fies. 2018a. Disponível em: http://www.fnde.gov.br/financiamento/fundeb/area-para-gestores/dados-estatisticos/item/ 4752-histórico. Acesso em: 9 jul. 2018.

FNDE. Fundo Nacional de Desenvolvimento da Educação. Sobre o Fies. 2018b. Disponível em: http://www.fnde.gov.br/financiamento/fies-graduacao/o-fies/sobre-o-fies. Acesso em: 1 jul. 2018.

FNDE. Fundo Nacional de Desenvolvimento da Educação. Microdados: Fies - 2018/1. Brasília: FNDE, 2018c. Disponível em: ftp://ftp2.fnde.gov.br/dadosabertos/FIES/ FINANCIAMENTO_CONCEDIDOS_SEMESTRE_1_2018.csv. Acesso em: 27 fev. 2020.

FNDE. Fundo Nacional de Desenvolvimento da Educação. Microdados: Fies - 2018/2. Brasília: FNDE, 2018d. Disponível em: ftp://ftp2.fnde.gov.br/dadosabertos/FIES/ FINANCIAMENTO_CONCEDIDOS_SEMESTRE_2_2018.csv. Acesso em: 27 fev. 2020.

FNDE. Fundo Nacional de Desenvolvimento da Educação. Fies: Repasse de CFT-E. 2018e. Disponível em: http://www.fnde.gov.br/financiamento/fies-graduacao/mantenedora-eies/repasse-de-cft-e. Acesso em: 9 jul. 2018.

FNDE. Fundo Nacional de Desenvolvimento da Educação. Fies: Recompra de CFT-E 2018/1. Brasília: FNDE, 2018f. Disponível em: ftp://ftp2.fnde.gov.br/dadosabertos/FIES/ RECOMPRA_SEMESTRE_1_2018.csv. Acesso em: 21 jul. 2020.

FNDE. Fundo Nacional de Desenvolvimento da Educação. Fies: Recompra de CFT-E 2018/2. Brasília: FNDE, 2018g. Disponível em: ftp://ftp2.fnde.gov.br/dadosabertos/FIES/ RECOMPRA_SEMESTRE_2_2018.csv. Acesso em: 21 jul. 2020.

FNDE. Fundo Nacional de Desenvolvimento da Educação. Fies: Repasse de CFT-E - 2018. Brasília: FNDE, 2018h. Disponível em: https://www.fnde.gov.br/index.php/centrais-deconteudos/publicacoes/category/221-

mantenedora_ies?download=13087:repasses_fies_ano_2018. Acesso em: 24 fev. 2020. 
FNDE. Fundo Nacional de Desenvolvimento da Educação. Estudantes inadimplentes poderão renegociar as dívidas com o Fies a partir do segundo semestre. FNDE, Brasília, 2018i. Disponível em: http://www.fnde.gov.br/acesso-a-informacao/institucional/area-deimprensa/noticias/item/11952-estudantes-inadimplentes-poderão-renegociar-as-dívidascom-o-fies-a-partir-do-segundo-semestre. Acesso em: 13 mar. 2019.

FNDE. Comitê Gestor do Fundo de Financiamento Estudantil. Nota Técnica $\mathbf{n}^{\circ}$ 3/2019/COFIN/CGSUP/DIGEF - anexo da resolução $n^{\circ}$ 37, de 18 de dezembro de 2019 Plano Trienal e quantidade de vagas. Brasília: CG-Fies, 2019a. Disponível em: https://www.fnde.gov.br/index.php/centrais-de-conteudos/publicacoes/category/51fies?download=13605:nota-tecnica-n3-2019. Acesso em: 13 jul. 2020.

FNDE. Fundo Nacional de Desenvolvimento da Educação. FIES - Financiamentos concedidos - Portal do FNDE. Brasília, 2019b. Disponível em: http://www.fnde. gov.br/financiamento/fies-graduacao/mantenedora-e-ies/financiamentos-concedidos. Acesso em: 12 mar. 2019.

FNDE. Fundo Nacional de Desenvolvimento da Educação. Portaria $\mathbf{n}^{\circ} 154$, de 3 de abril de 2019. Dispõe sobre o prazo para realização da renegociação dos contratos de financiamento concedidos com recursos do Fundo de Financiamento Estudantil (FIES), até o $2^{\circ}$ semestre de 2017, conforme estabelecido na Resolução n 28, de 31 de outubro de 2018. Brasília, 2019c. Disponível em: http://www.in.gov.br/materia/-/asset_publisher/Kujrw0TZC2Mb/content/ id/69871152/do1-2019-04-03-portaria-n-154-de-1-de-abril-de-2019-69871051. Acesso em: 24 jul. 2020.

FNDE. Fundo Nacional de Desenvolvimento da Educação. Repasse de CFT-E - Portal do FNDE. Brasília, 2019d. Disponível em: http://www.fnde.gov.br/financiamento/fiesgraduacao/mantenedora-e-ies/repasse-de-cft-e. Acesso em: 12 mar. 2020.

FNDE. Fundo Nacional de Desenvolvimento da Educação. Microdados: Fies - 2019/1. Brasília: FNDE, 2019e. Disponível em: ftp://ftp2.fnde.gov.br/dadosabertos/FIES/ FINANCIAMENTO_CONCEDIDOS_SEMESTRE_1_2019.csv. Acesso em: 27 fev. 2020.

FNDE. Fundo Nacional de Desenvolvimento da Educação. Microdados: Fies - 2019/2. Brasília: FNDE, 2019f. Disponível em: ftp://ftp2.fnde.gov.br/dadosabertos/FIES/ FINANCIAMENTO_CONCEDIDOS_SEMESTRE_2_2019.csv. Acesso em: 19 abr. 2020.

FNDE. Fundo Nacional de Desenvolvimento da Educação. Fies: Recompra de CFT-E 2019/1. Brasília: FNDE, 2019g. Disponível em: https://www.fnde.gov.br/olindaide/servico/Fies_Compra/versao/v1/odata/FiesCompra?\$filter=NuMesReferenciaLote le \%276\%27 and NuAnoReferenciaLote eq \%272019\%27 and NuMesReferenciaLote ne $\% 2710 \% 27$ and NuMesReferenciaLote ne \%2711\%27 and NuMesReferenciaLote. Acesso em: 21 jul. 2020.

FNDE. Fundo Nacional de Desenvolvimento da Educação. Fies: Recompra de CFT-E 2019/2. Brasília: FNDE, 2019h. Disponível em: https://www.fnde.gov.br/olindaide/servico/Fies_Compra/versao/v1/odata/FiesCompra?\$filter=NuAnoReferenciaLote eq $\% 272019 \% 27$ and (NuMesReferenciaLote ge \%277\%27 or NuMesReferenciaLote eq $\% 2710 \% 27$ or NuMesReferenciaLote eq $\% 2711 \% 27$ or NuMesReferenciaLote e. Acesso em: 21 jul. 2020. 
Reformulações e Implementação do Fies (1999-2020)

FNDE. Fundo Nacional de Desenvolvimento da Educação. Fies: Repasse de CFT-E - nov. 2019. Brasília: FNDE, 2019i. Disponível em: https://www.fnde.gov.br/index.php/centrais-deconteudos/publicacoes/category/51-fies?download=13694:repasses-novembro-2019. Acesso em: 24 fev. 2020.

FNDE. Fundo Nacional de Desenvolvimento da Educação. Fies: Repasse de CFT-E - fev. 2019. Brasília: FNDE, 2019j. Disponível em: https://www.fnde.gov.br/index.php/centrais-deconteudos/publicacoes/category/221-mantenedora_ies?download=13175:repa sses_fevereiro_2019_portal_transparencia. Acesso em: 24 fev. 2020.

FNDE. Fundo Nacional de Desenvolvimento da Educação. Fies: Repasse de CFT-E - mar. 2019. Brasília: FNDE, 2019k. Disponível em: https://www.fnde.gov.br/index.php/centrais-deconteudos/publicacoes/category/221-mantenedora_ies?download=13168:repasse-março2019. Acesso em: 24 fev. 2020.

FNDE. Fundo Nacional de Desenvolvimento da Educação. Fies: Repasse de CFT-E - abr. 2019. Brasília: FNDE, 2019l. Disponível em: https://www.fnde.gov.br/index.php/centrais-deconteudos/publicacoes/category/221mantenedora_ies?download=13241:repasses_abril_2019_fies. Acesso em: 24 fev. 2020.

FNDE. Fundo Nacional de Desenvolvimento da Educação. Fies: Repasse de CFT-E - mai. 2019. Brasília: FNDE, 2019m. Disponível em: https://www.fnde.gov.br/index.php/centrais-deconteudos/publicacoes/category/51-fies?download=13272:repasses_052019. Acesso em: 24 fev. 2020.

FNDE. Fundo Nacional de Desenvolvimento da Educação. Fies: Repasse de CFT-E - jun. 2019. Brasília: FNDE, 2019n. Disponível em: https://www.fnde.gov.br/index.php/centrais-deconteudos/publicacoes/category/51-fies?download=13286:repasse_junho_2019_fies.

Acesso em: 24 fev. 2020.

FNDE. Fundo Nacional de Desenvolvimento da Educação. Fies: Repasse de CFT-E - jul. 2019. Brasília: FNDE, 2019o. Disponível em: https://www.fnde.gov.br/index.php/centrais-deconteudos/publicacoes/category/221-

mantenedora_ies?download=13357:repasse_cfte_julho_2019. Acesso em: 24 fev. 2020.

FNDE. Fundo Nacional de Desenvolvimento da Educação. Fies: Repasse de CFT-E - ago. 2019. Brasília: FNDE, 2019p. Disponível em: https://www.fnde.gov.br/index.php/centrais-deconteudos/publicacoes/category/221-

mantenedora_ies?download=13436:repasse_agosto_2019_fies. Acesso em: 24 fev. 2020.

FNDE. Fundo Nacional de Desenvolvimento da Educação. Fies: Repasse de CFT-E - set. 2019. Brasília: FNDE, 2019q. Disponível em: https://www.fnde.gov.br/index.php/centrais-deconteudos/publicacoes/category/51-fies?download=13475:repasse-setembro-2019. Acesso em: 24 fev. 2020.

FNDE. Fundo Nacional de Desenvolvimento da Educação. Fies: Repasse de CFT-E - out. 2019. Brasília: FNDE, 2019r. Disponível em: https://www.fnde.gov.br/index.php/centrais-deconteudos/publicacoes/category/221-mantenedora_ies?download=13512:repasse-outubro2019. Acesso em: 24 fev. 2020. 
Reformulações e Implementação do Fies (1999-2020)

GILIOLI, Renato de Sousa Porto. Um balanço do FIES: desafios, perspectivas e metas do PNE. In: GOMES, Ana Valeska Amaral (Ed.). Plano Nacional de Educação: olhares sobre o andamento das metas. 1. ed. Brasília: Câmara dos Deputados, 2017. p. 195-226.

INEP. Instituto Nacional de Estudos e Pesquisas Educacionais Anísio Teixeira. Microdados: Censo da educação superior - 1999 (a). Brasília: INEP, 1999a. Disponível em: http://download.inep.gov.br/download/censo/1999/superior/miolo1_Sinopse_Superior99.pdf. Acesso em: 2 jun. 2018.

INEP. Instituto Nacional de Estudos e Pesquisas Educacionais Anísio Teixeira. Microdados: Censo da educação superior - 1999 (b). Brasília: INEP, 1999b. Disponível em: http://download.inep.gov.br/download/censo/1999/superior/miolo2_Sinopse_Superior99.pdf. Acesso em: 9 jul. 2018.

INEP. Instituto Nacional de Estudos e Pesquisas Educacionais Anísio Teixeira. Evolução do ensino superior - graduação 1980-1998. Brasília, 2000a. Disponível em: http://download .inep.gov.br/download/censo/1998/superior/evolucao_1980-1998.pdf. Acesso em: 10 mar. 2020.

INEP. Instituto Nacional de Estudos e Pesquisas Educacionais Anísio Teixeira. Microdados: Censo da educação superior - 2000. Brasília: INEP, 2000b. Disponível em: http://download .inep.gov.br/download/censo/2000/Superior/sinopse_superior-2000.pdf. Acesso em: 10 mar. 2020 .

INEP. Instituto Nacional de Estudos e Pesquisas Educacionais Anísio Teixeira. Microdados: Censo da educação superior - 2001. Brasília: INEP, 2001. Disponível em: http://download.inep .gov.br/download/censo/2001/Superior/Sinopse_Superior_2001.zip. Acesso em: 10 mar. 2020.

INEP. Instituto Nacional de Estudos e Pesquisas Educacionais Anísio Teixeira. Microdados: Censo da educação superior - 2002. Brasília: INEP, 2002. Disponível em: http://download.inep .gov.br/download/censo/2002/sinopse/Sinopse_2002_censosuperior.zip. Acesso em: 10 mar. 2020.

INEP. Instituto Nacional de Estudos e Pesquisas Educacionais Anísio Teixeira. Microdados: Censo da educação superior - 2003. Brasília: INEP, 2003. Disponível em: http://download.inep .gov.br/download/superior/2004/SES2003.zip. Acesso em: 10 mar. 2020.

INEP. Instituto Nacional de Estudos e Pesquisas Educacionais Anísio Teixeira. Microdados: Censo da educação superior - 2004. Brasília: INEP, 2004. Disponível em: http://download.inep .gov.br/download/superior/2004/Sinopse_2004_010206.zip. Acesso em: 10 mar. 2020.

INEP. Instituto Nacional de Estudos e Pesquisas Educacionais Anísio Teixeira. Microdados: Censo da educação superior - 2005. Brasília: INEP, 2005. Disponível em: http://download.inep .gov.br/download/superior/2005/Sinopse_2005a.zip. Acesso em: 10 mar. 2020.

INEP. Instituto Nacional de Estudos e Pesquisas Educacionais Anísio Teixeira. Microdados: Censo da educação superior - 2006. Brasília: INEP, 2006. Disponível em: http://download.inep .gov.br/download/superior/censo/2006/Sinopse_EducacaoSuperior_2006.zip. Acesso em: 10 mar. 2020. 
Reformulações e Implementação do Fies (1999-2020)

INEP. Instituto Nacional de Estudos e Pesquisas Educacionais Anísio Teixeira. Microdados: Censo da educação superior - 2007. Brasília: INEP, 2007. Disponível em: http://download.inep .gov.br/download/superior/censo/2007/Sinopse2007.zip. Acesso em: 10 mar. 2020.

INEP. Instituto Nacional de Estudos e Pesquisas Educacionais Anísio Teixeira. Microdados: Censo da educação superior - 2008. Brasília: INEP, 2008. Disponível em: http://download. inep.gov.br/download/censo/2008/sinop_sup_2008_versao_preliminar.zip. Acesso em: 10 mar. 2020.

INEP. Instituto Nacional de Estudos e Pesquisas Educacionais Anísio Teixeira. Microdados: Censo da educação superior - 2009. Brasília: INEP, 2009. Disponível em: http://download .inep.gov.br/download/superior/censo/2009/sinopse_da_educacao_superior_2009.zip.

Acesso em: 10 mar. 2020.

INEP. Instituto Nacional de Estudos e Pesquisas Educacionais Anísio Teixeira. Microdados: Censo da educação superior - 2010. Brasília: INEP, 2010. Disponível em: http://download.inep .gov.br/informacoes_estatisticas/2010/sinopses_estatisticas_ed_superior/sinopse_educacao _superior_2010_2.zip. Acesso em: 10 mar. 2020.

INEP. Instituto Nacional de Estudos e Pesquisas Educacionais Anísio Teixeira. Microdados: Censo da educação superior - 2011. Brasília: INEP, 2011. Disponível em: http://download.inep .gov.br/informacoes_estatisticas/sinopses_estatisticas/sinopses_educacao_superior/sinopse _educacao_superior_2011.zip. Acesso em: 10 mar. 2020.

INEP. Instituto Nacional de Estudos e Pesquisas Educacionais Anísio Teixeira. Microdados: Censo da educação superior - 2012. Brasília: INEP, 2012. Disponível em: http://download .inep.gov.br/informacoes_estatisticas/sinopses_estatisticas/sinopses_educacao_superior/sin opse_educacao_superior_2012.zip. Acesso em: 10 mar. 2020.

INEP. Instituto Nacional de Estudos e Pesquisas Educacionais Anísio Teixeira. Microdados: Censo da educação superior - 2013. Brasília: INEP, 2013. Disponível em: http://download .inep.gov.br/informacoes_estatisticas/sinopses_estatisticas/sinopses_educacao_superior/sin opse_educacao_superior_2013.zip. Acesso em: 10 mar. 2020.

INEP. Instituto Nacional de Estudos e Pesquisas Educacionais Anísio Teixeira. Microdados: Censo da educação superior - 2014. Brasília: INEP, 2014. Disponível em: http://download .inep.gov.br/informacoes_estatisticas/sinopses_estatisticas/sinopses_educacao_superior/sin opse_educacao_superior_2014.zip. Acesso em: 10 mar. 2020.

INEP. Instituto Nacional de Estudos e Pesquisas Educacionais Anísio Teixeira. Microdados: Censo da educação superior - 2015. Brasília: INEP, 2015. Disponível em: http://download.inep.gov.br/informacoes_estatisticas/sinopses_estatisticas/sinopses_educac ao_superior/sinopse_educacao_superior_2015.zip. Acesso em: 10 mar. 2020.

INEP. Instituto Nacional de Estudos e Pesquisas Educacionais Anísio Teixeira. Microdados: Censo da educação superior - 2016. Brasília: INEP, 2016. Disponível em: http://download .inep.gov.br/informacoes_estatisticas/sinopses_estatisticas/sinopses_educacao_superior/sin opse_educacao_superior_2016.zip. Acesso em: 10 mar. 2020.

INEP. Instituto Nacional de Estudos e Pesquisas Educacionais Anísio Teixeira. Microdados: Censo da educação superior - 2017. Brasília: INEP, 2017. Disponível em: 
http://download.inep.gov.br/informacoes_estatisticas/sinopses_estatisticas/sinopses_educac ao_superior/sinopse_educacao_superior_2017.zip\%0A. Acesso em: 10 mar. 2020.

INEP. Instituto Nacional de Estudos e Pesquisas Educacionais Anísio Teixeira. Microdados: Censo da educação superior - 2018. Brasília: INEP, 2018. Disponível em: http://download.inep.gov.br/informacoes_estatisticas/sinopses_estatisticas/sinopses_educac ao_superior/sinopse_educacao_superior_2018.zip. Acesso em: 10 mar. 2020.

MENDES, Marcos José. A despesa federal em educação: 2004-2014. Brasília, 2015. Disponível em: https://www12.senado.leg.br/publicacoes/estudos-legislativos/tipos-deestudos/boletins-legislativos/bol26. Acesso em: 18 jul. 2018.

NASCIMENTO, Paulo A. Meyer M.; LONGO, Gustavo Frederico. Qual o custo implícito do FIES para o contribuinte brasileiro?Radar. Brasília: IPEA, 2016. Disponível em: http://www.ipea.gov.br/portal/images/stories/PDFs/radar/radar46_art02.pdf. Acesso em: 1 mar. 2018.

NOVAES, Marcos Adriano Barbosa de. Financiamento público para o ensino superior privado no Brasil: uma análise crítica do Fies e Prouni. 2017. Dissertação (Mestrado em Educação) - Universidade Estadual do Ceará, Fortaleza, 2017. Disponível em: http://www.uece.br/maie/dmdocuments/dissertacao_marcos_adriano_barbosa_de_novaes.p df. Acesso em: 21 nov. 2017.

QUEIROZ, Viviane De. Fundo de financiamento estudantil (FIES): uma nova versão do CREDUC. Universidade e Sociedade, n. 55, p. 14, 2015. Disponível em: http://www.andes. org.br/imprensa/publicacoes/imp-pub-1095164128.pdf. Acesso em: 1 mar. 2018.

ROSSETTO, Cristina B. de Souza; GONÇALVES, Flávio de Oliveira. Equidade na educação superior no Brasil: uma análise multinomial das políticas públicas de acesso. Dados, Rio de Janeiro, v. 58, n. 3, p. 791-824, 2015. Disponível em: http://www.scielo.br/scielo .php?script=sci_arttext\&pid=S0011-52582015000300791\&lng=pt\&tIng=pt. Acesso em: 21 nov. 2017.

SGUISSARDI, Valdemar. Educação superior no Brasil: democratização ou massificação mercantil? Educação \& Sociedade, Campinas, v. 36, n. 133, p. 867-889, 2015. Disponível em: http://www.scielo.br/pdf/es/v36n133/1678-4626-es-36-133-00867.pdf. Acesso em: 19 nov. 2017.

SILVA, Maíra Teixeira; SOARES, Felipe Furini. Educação na Bolsa de Valores: o FIES e o ensino superior privado. FINEDUCA, Revista de Financiamento da Educação, v. 9, n. 1, p. 1-17, 2019. Disponível em: https://seer.ufrgs.br/fineduca/article/view/74708/52323. Acesso em: 19 nov. 2017.

SOUZA, Jessé. A elite do atraso. Rio de Janeiro: Estação Brasil, 2019. 
Reformulações e Implementação do Fies (1999-2020)

Rodrigo Meleu das Neves é analista de Tecnologia de Informação do Centro de Processamento de Dados da UFRGS. Mestre em Administração, Área de Concentração em Sistemas de Informação e de Apoio à Decisão (EA/UFRGS). Doutor em Educação (PPGEdu/UFRGS).

ORCID: http://orcid.org/0000-0002-8587-4481

E-mail: rodrigon@cpd.ufrgs.br

Nalú Farenzena é professora Titular do Departamento de Estudos Especializados (DEE) e do Programa de Pós-Graduação em Educação (PPGEdu) da Faculdade de Educação da Universidade Federal do Rio Grande do Sul (FACED/UFRGS). Área de concentração: Estudos de Política e Gestão da Educação. Presidenta da Associação Nacional de Pesquisa em Financiamento da Educação (Fineduca).

ORCID: http://orcid.org/0000-0003-2582-5925

E-mail: nalu.farenzena@gmail.com

Denise Lindstrom Bandeira é professora Associada do Departamento de Ciências Administrativas e do Programa de Pós-Graduação em Administração da Escola de Administração da Universidade Federal do Rio Grande do Sul (EA/UFRGS), Área de Concentração: Sistemas de Apoio à Decisão e Modelagem Quantitativa. Coordenadora da área de Produção e Sistemas da Escola de Administração.

ORCID: http://orcid.org/0000-0003-3161-2985

E-mail: dlbandeira@ea.ufrgs.br 


\section{Editores do volume 11}

Márcia Aparecida Jacomini - Universidade Federal de São Paulo, Brasil

José Marcelino de Rezende Pinto - Universidade de São Paulo, Brasil

\section{Comitê Editorial}

Nalú Farenzena - Universidade Federal do Rio Grande do Sul, Brasil

Juca Gil - Universidade Federal do Rio Grande do Sul, Brasil

Theresa Adrião - Universidade Estadual de Campinas, Brasil

Ângelo Ricardo de Souza - Universidade Federal do Paraná, Brasil

\section{Conselho Editorial}

\section{Alejandro Morduchowicz}

Universidad Pedagógica, Provincia de Buenos Aires, Argentina

Andréa Barbosa Gouveia

Universidade Federal do Paraná, Brasil

Fernanda Saforcada

Universidade de Buenos Aires, Argentina

Jacques Velloso

Universidade de Brasília, Brasil

João Monlevade

Senado Federal, Brasil

Jorge Abrahão de Castro

Instituto de Pesquisa Econômica Aplicada / IPEA, Brasil

Lisete Regina Gomes Arelaro

Universidade de São Paulo, Brasil

Luis Carlos Sales

Universidade Federal do Piauí, Brasil

Luiz de Sousa Junior

Universidade Federal da Paraíba, Brasil

Luiz Fernandes Dourado

Universidade Federal de Goiás, Brasil

Magna França

Universidade Federal do Rio Grande do Norte, Brasil

Marcos Edgar Bassi

Universidade Federal de Santa Catarina, Brasil

Maria Angélica Pedra Minhoto

Universidade Federal de São Paulo, Brasil

Maria Beatriz Luce

Universidade Federal do Rio Grande do Sul, Brasil

Maria Dilnéia Espíndola Fernandes

Universidade Federal de Mato Grosso do Sul, Brasil

Nelson Cardoso do Amaral

Universidade Federal de Goiás, Brasil

Nicholas Davies

Universidade Federal Fluminense, Brasil

Robert E. Verhine

Universidade Federal da Bahia, Brasil

Romualdo Portela de Oliveira

Universidade de São Paulo, Brasil

Rosana Gemaque Rolim

Universidade Federal do Pará, Brasil

Rubens Barbosa de Camargo

Universidade de São Paulo, Brasil

Theresa Adrião

Universidade Estadual de Campinas, Brasil

Tristan McCowan

University of London, Reino Unido

Vera Jacob

Universidade Federal do Pará, Brasil

Vera Peroni

Universidade Federal do Rio Grande do Sul, Brasil

Vitor Henrique Paro

Universidade de São Paulo, Brasil

\section{Equipe editorial}

Apoio ao Comitê Editorial: Caio Cabral da Silva

Diagramação, Revisão de português e normalização: Edson Leonel de Oliveira

Revisão de inglês: Sabrina Ferreira

Fineduca - Revista de Financiamento da Educação

Associação Nacional de Pesquisa em

Financiamento da Educação

e-mail: revista.fineduca@gmail.com | site: http://seer.ufrgs.br/fineduca 